\title{
Assessment of the ocean circulation in the Azores region as predicted by a numerical model assimilating altimeter data from Topex/Poseidon and ERS-1 satellites
}

\author{
T. Mailly ${ }^{1}$, E. Blayo ${ }^{2}$, J. Verron ${ }^{1}$ \\ ${ }^{1}$ Laboratoire des Ecoulements Géophysiques et Industriels, BP 53, 38041 Grenoble cedex 9, France \\ ${ }^{2}$ Laboratoire Modélisation et Calcul, BP 53, 38041 Grenoble cedex 9, France, e-mail: eric.blayo@imag.fr
}

Received: 25 July 1996 / Revised: 27 March 1997 / Accepted 8 April 1997

\begin{abstract}
Two years of altimetric data from Topex/ Poseidon (October 1992-September 1994) and ERS-1 (October 1992-December 1993) were assimilated into a numerical model of the North Atlantic. The results of these simulations are analysed in the Azores region to assess the performance of our model in this particular region. Maps of instantaneous dynamic topography and transports show that the model performs well in reproducing the velocities and transports of the Azores Front. Drifter data from the Semaphore experiment are also used to study the correlation between the drifter velocities and the corresponding model velocities. Some interesting oceanographic results are also obtained by examining the seasonal and interannual variability of the circulation and the influence of bathymetry on the variability of the Azores Front. Thus, on the basis of our two year experiment, it is possible to confirm the circulation patterns proposed by previous studies regarding the seasonal variations in the origin of the Azores Current. Moreover, it is shown that the Azores Current is quite narrow in the first year of assimilation (1992-1993), but becomes much wider in the second year (1993-1994). The role of the bathymetry appears important in this area since the mesoscale activity is shown to be strongly related to the presence of topographic slopes. Finally, spectral analyses of sea-level changes over time and space are used to identify two types of wave already noticed in other studies: a wave with $(300 \mathrm{~km})^{-1}$ wave number and $(120 \text { days })^{-1}$ frequency, which is characteristic of mesoscale undulation, and a wave with $(600 \mathrm{~km})^{-1}$ wave number and $(250$

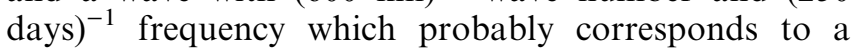
Rossby wave generated in the east of the basin.
\end{abstract}

\section{Introduction}

In the past decade, our understanding of ocean circulations has considerably improved thanks to satellite altimetry. Although the first encouraging results using satellite altimetry were obtained with the Seasat mission in 1978, full exploitation of the sea-surface height measurements only really began with the Geosat mission (1986-1989). This allowed significant progress to be made in our knowledge of both mesoscale and largescale ocean dynamics. For more details, the reader is referred to the special issues of the Journal of Geophysical Research [vol 95 (C3) 1990 and vol 95 (C10) 1990]. Further satellite launches occurred more recently (ERS-1 in July 1991, Topex/Poseidon in August 1992, ERS-2 in April 1995) which provided the possibility for continuous and synoptic monitoring of the ocean dynamic topography as, for example, described in the special issues of the Journal of Geophysical Research [vol 99 (C12) 1994 and vol 100 (C12) 1995] on the different results obtained using Topex/Poseidon measurements.

These satellite data are now increasingly used for assimilation into numerical models (for example, the review paper by Ghil and Malanotte-Rizzoli (1991) on the new perspectives in data assimilation). In the SIMAN project (SIMulation de l'Atlantique Nord), the Grenoble group thus developed a QG model for the ocean circulations in the North Atlantic which assimilates the satellite altimetric observations through a simple nudging technique (Verron et al., 1992; Blayo et al., 1994). Until now, the performance of this model has been analysed mainly in the Gulf Stream area (Blayo et al., 1996). It has been shown that the model is able to reproduce, in a deterministic way, many characteristics of this major feature of the North Atlantic Ocean. The altimetric information is of crucial importance for this purpose, since the model without assimilation performs quite poorly. However, it is also of interest to assess the ability of this North Atlantic model to reproduce the 
circulation in areas of lower energy levels such as those situated east of the Mid-Atlantic Ridge (MAR). In these regions, the altimetric signal is relatively weak compared with that obtained for the western regions and assimilation of data may not be so efficient in constraining the ocean model. The present work thus focuses on a region of particular interest in the northeast Atlantic, the Azores region.

In this region, the dominant feature is the Azores current which flows eastward to the south of the archipelago. This current is a remote branch of the Gulf Stream, as can be seen on the dynamic topography map produced by Stommel et al. (1978) and, more recently, in the North Atlantic circulation pattern proposed by Krauss (1986) and Sy (1988) (see Fig. 1). The Azores Current includes a strong narrow current associated with an intense mesoscale activity, clearly identified in several field studies (Käse and Siedler, 1982; Siedler et al., 1985; Käse et al., 1986; Sy, 1988; Maillard and Käse, 1989). This narrow well-defined current is the Azores Front which should be distinguished from the Azores Current, a term which generally refers to the regional current system. Thus, the Azores Current designates the global branch which originates in the Gulf Stream, flows over the MAR and contributes to the main anticyclonic subtropical recirculation. It is mostly relevant as a mean circulation pattern over time, whereas the Azores Front and the associated eddy fields are more identifiable in instantaneous circulation patterns. The Azores Front makes a predominant contribution to overall transport in the area and is observed permanently or quasi-permanently (Siedler et al., 1985; Maillard and Käse, 1989).

The objective of this study is to assess the results of the QG model assimilating Topex/Poseidon (T/P) and

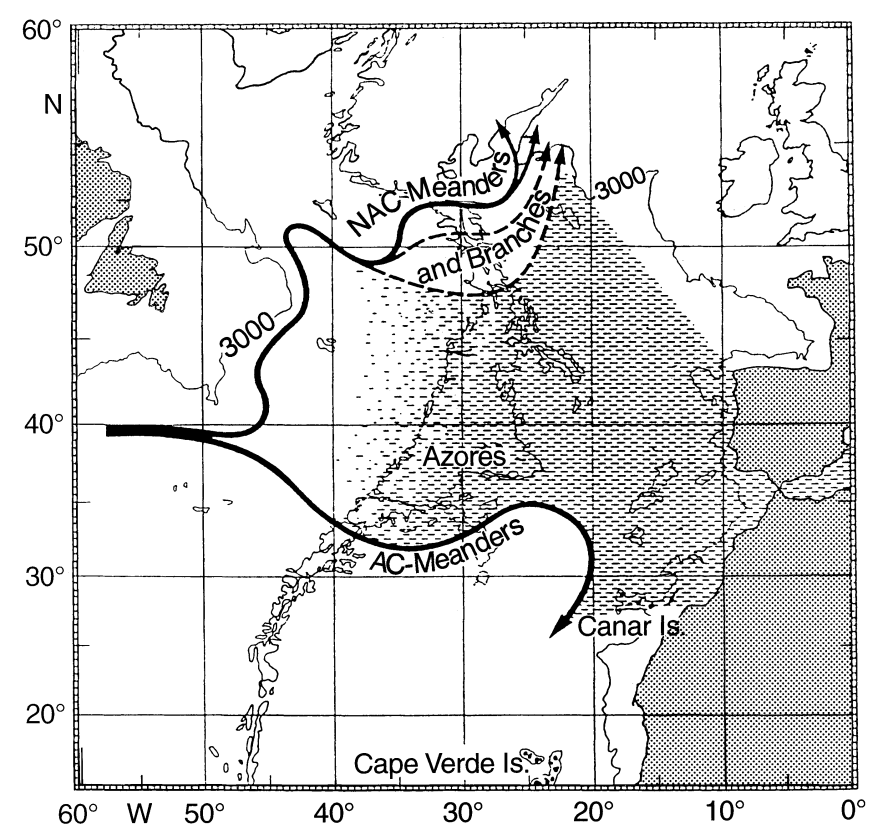

Fig. 1. Schematic ocean surface circulation in the Northeast Atlantic after Sy (1988). Shading corresponds to the extension of the Mediterranean water
ERS-1 altimeter data (for respective periods of October 1992 - September 1994 and October 1992 - December 1993), by comparing them with results from studies conducted in the Azores region on one hand and from studies using the drifter measurements of the Semaphore experiment (Eymard et al., 1996) on the other. The first step concerned essentially the statistical aspects, namely the velocity, transport and energy properties, as well as the characteristic temporal and spatial scales of mesoscale variability. The drifters in the Semaphore experiment provide local velocity measurements for the period of investigation which can be used to assess deterministically the ability of the model to reproduce the spatial and temporal aspects of the local ocean flows. Once validated, the model would provide for a more complete representation of the Azores Front for the 1993-1994 period. Section 2 describes the model and data used in our experiments. Results and comparative analyses are presented in the following sections: Sect. 3 deals with velocities and transports, Sect. 4 describes the comparison with Lagrangian floats, Sect. 5 examines the variability, while the temporal and spatial scales are analysed in Sect. 6. Section 7 presents a discussion and the study conclusions.

\section{Model and data used}

\section{The model}

The model used in this study is the QG model which has been developed by the Grenoble group over several years. It will not be described in detail here, but for more information the reader is referred to Blayo et al. (1994, 1996). The main features of the model may be summarised as follows: it is a multilayer QG finite-difference model using spherical coordinates, and the rigid lid and $\beta$-plane approximations. The model is forced by the wind-stress curl and the energy is dissipated by lateral friction in all layers, and by bottom friction in the deeper layer of the ocean. Along the solid boundaries, a no-slip condition is applied, the formulation of which involves a simple viscous boundary-layer parametrisation (Verron and Blayo, 1996). The model domain covers the North Atlantic ocean between $20^{\circ} \mathrm{N}$ and $60^{\circ} \mathrm{N}$. The horizontal resolution is $1 / 6^{\circ}$ in both directions. The vertical resolution is six-layered and the respective layers are centred at depths of 50, 200, 450, 800, 1750 and $3750 \mathrm{~m}$. Open boundaries at $20^{\circ} \mathrm{N}$ and $60^{\circ} \mathrm{N}$ and at the Florida Straits are defined in terms of mixed numerical conditions: a radiation condition for the outflow variability and a climatological relaxation for the mean flows determined from available in situ observations. In the upper four layers, the following climatological inflows are thus imposed: $26 \mathrm{~Sv}$ at the Florida Straits, $4 \mathrm{~Sv}$ for the Antilles Current and $6 \mathrm{~Sv}$ for the Labrador Current. Climatological outflows are $19 \mathrm{~Sv}$ for the anticyclonic subtropical circulation, and $17 \mathrm{~Sv}$ for the cyclonic subpolar circulation. The water mass transport from the Gulf Stream system which would feed the North Atlantic Drift is therefore $11 \mathrm{~Sv}$, in agreement 
with the synthetic analysis by Schmitz and McCartney (1993). In the bottom two layers, the specified flows amount to $12 \mathrm{~Sv}$ for the deep Western Boundary Current flowing southward. The wind data are taken from ECMWF atmospheric model analyses with daily sampling and a spatial resolution of $1.25^{\circ}$ by $1.25^{\circ}$. This is a noticeable improvement over previous simulations where the wind was considered constant in time. Real values are used for the bathymetry, these being taken from the ETOPO5 dataset. In the areas where the amplitude of the topography is too large to satisfy the QG approximation, the deep circulation is controlled by the topographic gradients, which force the flow to follow mainly the $f / h$ contours. Our model does not consider the Mediterranean inflow from the Straits of Gibraltar and cannot therefore reproduce meddies (Armi and Zenk, 1984), which in any case would not be properly reproduced in a QG formulated model.

\section{Satellite data and the assimilation technique}

Two satellite altimetric datasets were used: one obtained by $\mathrm{T} / \mathrm{P}$ (a 10-day repeat period satellite with a track interval of $315 \mathrm{~km}$ at the Equator) from October 1992 to September 1994, the other by ERS-1 (a 35-day repeat period satellite with a finer track interval of about $80 \mathrm{~km}$ at the Equator) from October 1992 to December 1993. The ERS-1 data were recalibrated with T/P data for the period of simultaneous flight in order to take advantage of the greater accuracy of $\mathrm{T} / \mathrm{P}$ orbit determination (Le Traon et al., 1995). Simultaneous assimilation of these two datasets was performed for a period of two years, taking advantage of all available information. In this respect, Blayo et al. (1997) and Hernandez et al. (1995) have already demonstrated the advantages of using $\mathrm{T} / \mathrm{P}$ data and ERS-1 data simultaneously to reconstruct the ocean circulation.

In fact, only residuals of the altimeter measurements, i.e. measurements referenced to some mean sea-surface, are sufficiently reliable for assimilation purposes. The mean sea-surface provided by the altimeter itself is not reliable enough, especially at the mesoscales, due to our incomplete knowledge of the geoid. The quantity to be assimilated in the model is the sea-surface topography or sea-surface height $h$ (SSH) which, in a layered QG model, is proportional to the surface layer stream function $\psi_{1}\left(h=f_{0} / g \psi_{1}\right)$. To reconstruct this SSH data, some mean sea surface height (MSSH) must be added to the altimetric residuals. This MSSH must correspond as far as possible to the mean ocean state during the period of investigation. To obtain such a surface, an iterative method was used, as described by Blayo et al. (1994). Given a particular set of residuals $h^{\prime}$ and a first guess $\bar{h}_{0}$ (itself an MSSH provided, for example, by previous experiments or by an inverse model), we compute $h_{0}=\bar{h}_{0}+h^{\prime}$. This SSH $h_{0}$ is assimilated by our model, and we can then compute $\bar{h}_{1}$, the time average of the model results over the period relative to this particular data set. This field $\bar{h}_{1}$ differs from $\bar{h}_{0}$ because of the input from the altimeter data and from the model dynamics.
This process is then iterated: given an MSSH $\bar{h}_{n}(n \geq 1), h_{n}=\bar{h}_{n}+h^{\prime}$ is assimilated by the model. Then the new time average $\bar{h}_{n+1}$ is computed from the model results. This process is repeated until the model results no longer differ significantly from one iteration to the other, even in the deep ocean where the circulation is the slowest to adjust (the exact criterion is that the relative Rms between the mean stream functions from two successive iterations be less than $1 \%$ in each layer). The first-guess $\bar{h}_{0}$ that we used in our earlier studies was provided by the inverse model of Mercier et al. (1993). Using several times the iterative procedure with Geosat residuals first, and then the first year of $\mathrm{T} / \mathrm{P}$ residuals, we obtained a converged MSSH. Then, using this $\mathrm{MSSH}_{0}$, assimilation was performed over the two-year assimilation cycle with ERS-1 and T/P residuals. The average solution for the SSH corresponding to this period provides a new $\mathrm{MSSH}_{1}$, which should in principle be more representative of the real MSSH during that time period. $\mathrm{MSSH}_{1}$ is the MSSH which was added to the residuals in the assimilation procedure for the present experiment.

To assimilate per se, a simple sequential nudging technique is used along the ground tracks of the satellites. At each instant $t$, and at each grid-point $P$ located under a satellite track, the model is "nudged" towards the data with a relaxation term of the type

$r(P, t)\left[h_{\text {model }}(P, t)-h_{\text {obs }}(P, t)\right]$

where $h_{\text {model }}(P, t)$ is the model solution at point $P$ and at time $t$, and where $h_{o b s}(P, t)$ is obtained from a linear interpolation between the values measured by the satellites at point $P$, at times $t_{\text {prev }}$ and $t_{\text {next }}$, i.e. at the passing over point, prior to and following instant $t$. The relaxation factor $r(P, t)$ is written as

$r_{0} \exp \left[-\min \left(t-t_{\text {prev }} ; t_{\text {next }}-t\right) / \tau_{0}\right]$

so that it is maximum at the time the satellite passes overhead and minimum between two successive passages. The nudging time scale (inversely proportional to $r_{0}$ ) is fixed to one day following the study by Verron (1992), and the persistance time scale $\tau_{0}$ chosen here is 5 days.

\section{Velocities and transports}

In this section, the model's results are compared first with those found in the literature to assess the model's performance from a general, statistical point of view, then with results from the Semaphore experiment for a more deterministic assessment.

\section{Instantaneous dynamic topography and velocities}

The model's prediction of the Azores Front in the upper surface layers is presented in Fig. 2. This shows instantaneous 'pictures' of the dynamic topography in the Azores region at four-month intervals. The front, together with strong eddy activity, is clearly visible around latitude $34^{\circ} \mathrm{N}$. Eddies can in fact be interpreted 

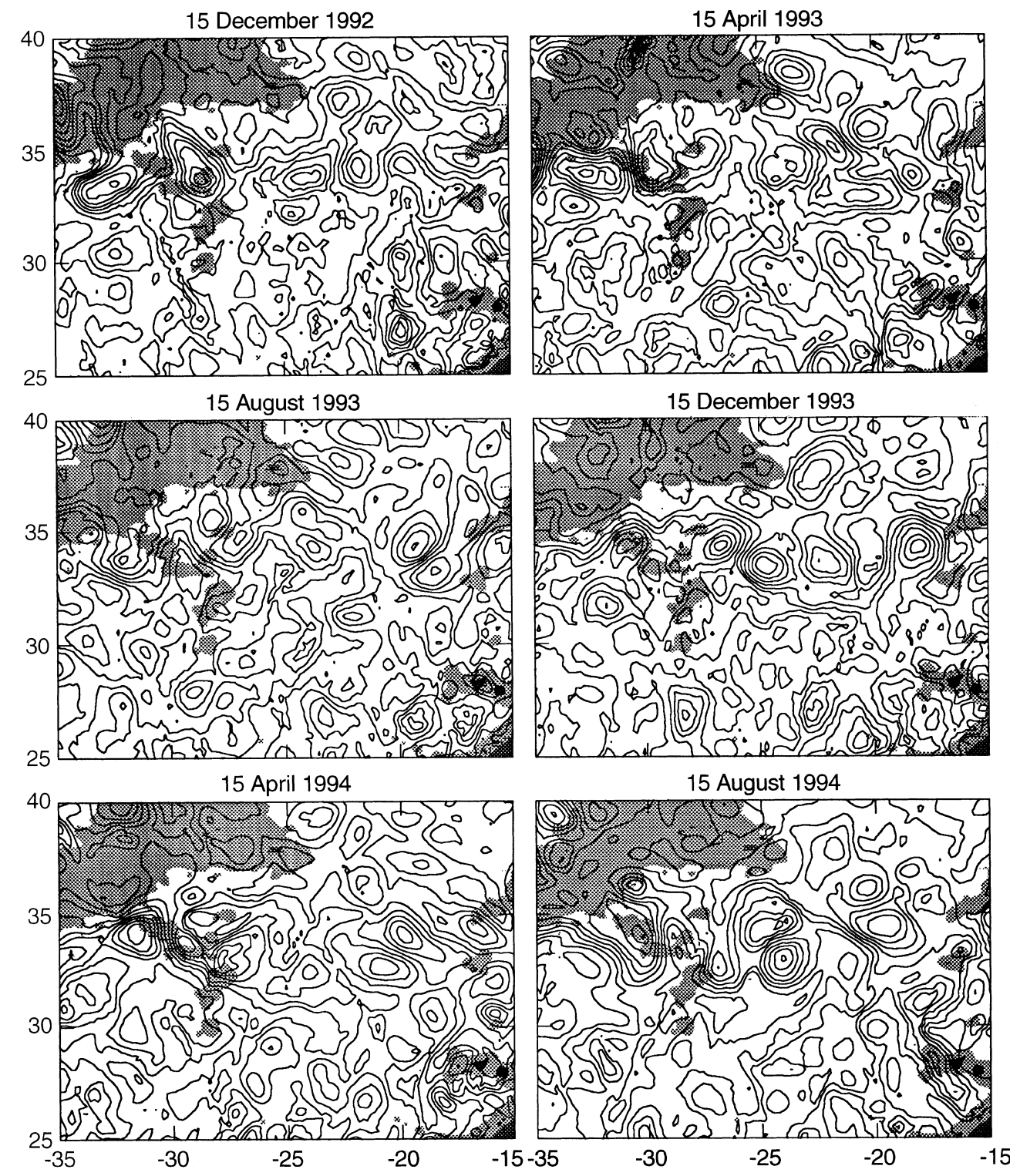

15 April 1993

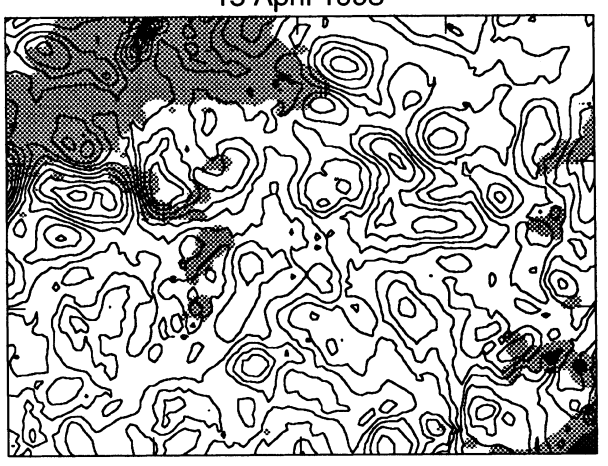

15 December 1993

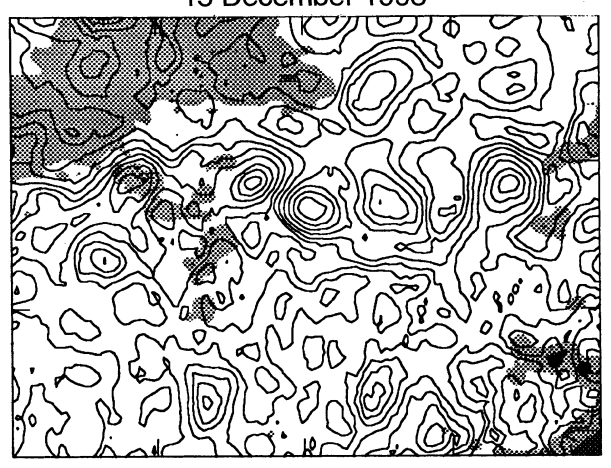

15 August 1994 as the signature of the front, as they are mostly generated by its meandering. The eddy structures identified around $20^{\circ} \mathrm{W}$ resemble those found in the pattern proposed by Käse and Siedler (1982) which was obtained from hydrographic observations in MarchApril 1982 around $22^{\circ} \mathrm{W}, 34^{\circ} \mathrm{N}$, see their Fig. 2. Similar estimates are also found for the current width (approximately $60 \mathrm{~km})$, the maximum velocity $(25 \mathrm{~cm} / \mathrm{s})$, and the typical size of the eddy structures $(200 \mathrm{~km})$. The model predicts instantaneous velocities at $50 \mathrm{~m}$ depth, reaching some 20 to $25 \mathrm{~cm} / \mathrm{s}$ in the middle of the front. Measurements from mooring $276\left(22^{\circ} \mathrm{W}, 33^{\circ} \mathrm{N}\right)$ by Siedler et al. (1985) give maximum surface (actually 200 $\mathrm{m}$ depth) velocities slightly greater than $20 \mathrm{~cm} / \mathrm{s}$. Schmitz et al. (1988), also using current meters, found a maximum velocity of $30 \mathrm{~cm} / \mathrm{s}$ at $470 \mathrm{~m}$ depth at $24^{\circ} \mathrm{W}$, $32^{\circ} \mathrm{N}$. Thus, the model apparently provides good estimates of instantaneous velocities. In Fig. 2, it may also be noted that the front computed is present throughout the period of simulation, even though it seems less pronounced at times. This is in agreement with the work by Siedler et al. (1985) who, after analysing 3 years (1981-1983) of current meter measurements at $22^{\circ} \mathrm{W}, 33.5^{\circ} \mathrm{N}$, concluded that the front was a persistent or a quasi-persistent phenomenon in this area.

\section{Instantaneous transports in the front}

The instantaneous transports predicted by the model are in general quite realistic with regard to what we actually know of the ocean. For example, the surface transport was computed by integrating the model stream functions over the first four layers within the thermocline, which represent an overall depth of $1000 \mathrm{~m}$. Examples of instantaneous transports from 0 to $1000 \mathrm{~m}$ given by the model are presented in Fig. 3. Three values, in particular those concerning the transport of the front, are compared with transports computed from in situ measure- 


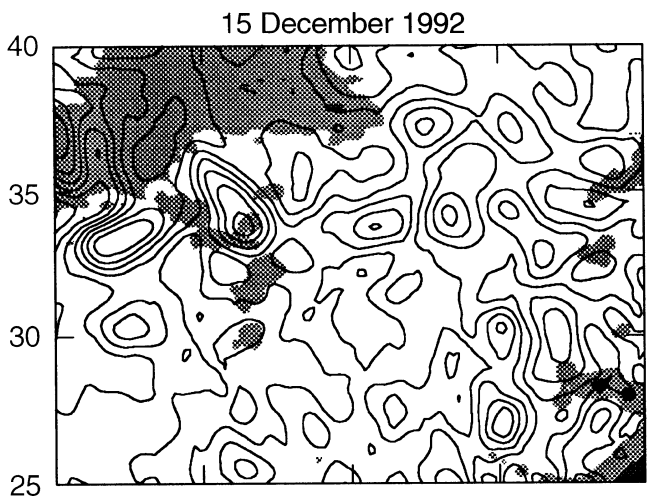

15 August 1993

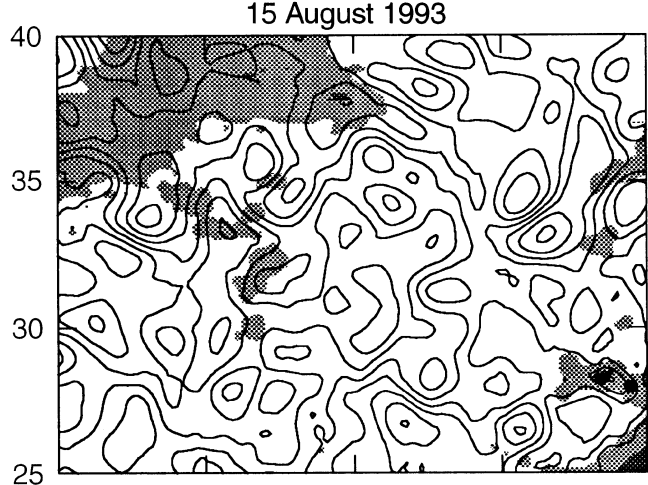

15 April 1994

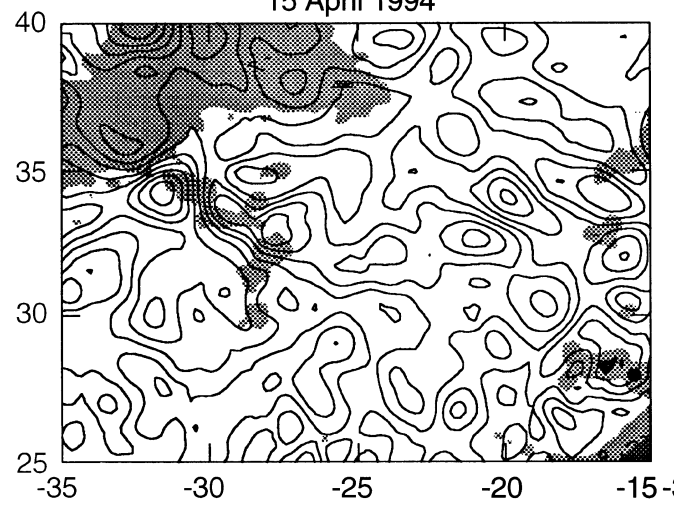

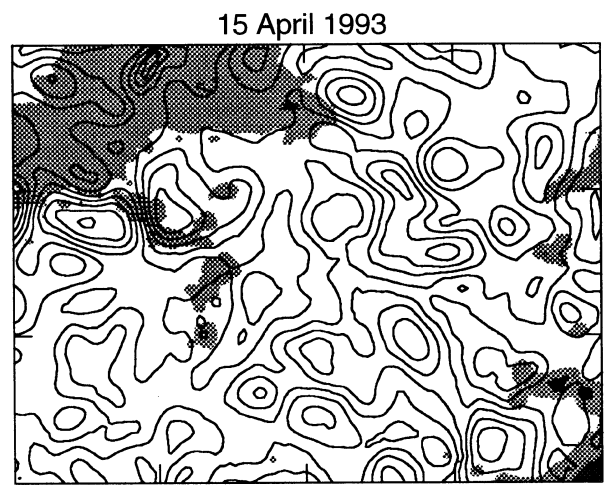

15 December 1993

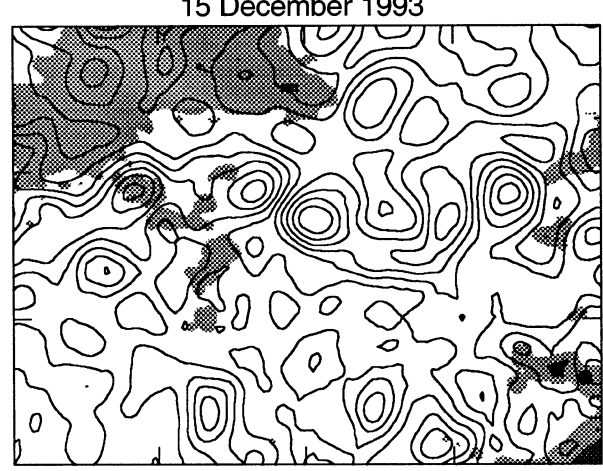

15 August 1994

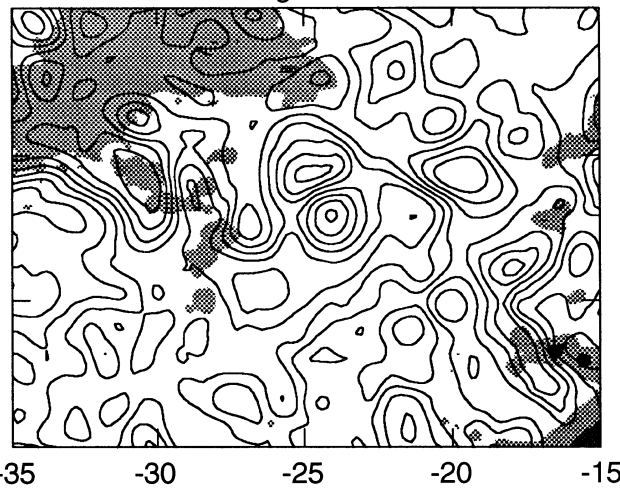

Fig. 3. Instantaneous surface transport $(0-1000 \mathrm{~m})$ in the Azores region as predicted by the model on Dec. 15, 1992, Apr. 15, 1993, Aug. 15, 1993, Dec. 15, 1993, Apr. 15, 1994 and Aug. 15, 1994. (CI: 2 Sv). Shading corresponds to the regions where the depth is less than $3000 \mathrm{~m}$ ments. The latter can be considered as instantaneous only if the duration of the measurements is less than three months, as indicated by the time-scales of the mesoscale activity in this region (see Sect. 6). The instantaneous transport values provided by the model are thus in agreement with the results of Sy (1988) and Käse and Siedler (1982). Sy (1988) estimates a 12-Sv transport for the front at $29^{\circ} \mathrm{W}$, based on a survey in the summer of 1983, where $6 \mathrm{~Sv}$ is given by the model at $29^{\circ} \mathrm{W}$ (Fig. 3) for the instantaneous transport. Käse and Siedler (1982) observed a 10-Sv transport above $1500 \mathrm{~m}$, concentrated in a $60-\mathrm{km}$ wide jet in the area $\left(18-24^{\circ} \mathrm{W}\right.$, $32-36^{\circ} \mathrm{N}$ ) in the period March-April 1982, while transports of $6 \mathrm{~Sv}$ can be seen at $20^{\circ} \mathrm{W}$ in the eddy structures in Fig. 3. It should be noted that these comparisons are valid since Stramma (1984) showed that the level of nomotion is not of major importance for the computation of transports in this region. Whatever the level of nomotion used comprised between 1000 and $2500 \mathrm{~m}$ and whatever the depth of integration, 1000 or $2000 \mathrm{~m}$, the resulting computed transport does not vary a lot (see his Table 2).

The transports predicted by the model therefore seem realistic even if they are less than the observed ones. Two observations may be made, however, with regard to eddy transport. First, the ratio of the eddy to the total transport of the front meanders seems to be quite large. This arises from the fact that the mean transport is imposed through an independent climatology (our MSSH, see Sect. 2). The chosen climatology does not provide for a sufficient transport in the Azores Current, which explains the too weak instantaneous transport obtained in our simulations. Therefore, the eddy/total transport ratio as identified through the assimilation process becomes greater than in reality. In addition, it is observed in the numerical simulation that the eddy/total transport is greater in the eastern part of the domain (around $20^{\circ} \mathrm{W}$ ) than in the western part (around $30^{\circ} \mathrm{W}$ ). This is in agreement with the comments in the following section on front variability. As noted by Le Traon and 
De Mey (1994), even if the flow from the front is directed for a large part southward around $25^{\circ} \mathrm{W}$, the main area of variability shows up as a zonal strip at approximately $20^{\circ} \mathrm{W}$.

\section{Seasonal variations in mean transport}

The Azores Current is considered here in its widest sense and includes the upstream part, i.e. before and over the MAR. Two years of satellite data are available, that is two summers and two winters, and these are used to analyse some of the seasonal variability in the mean transport. Winter (from October to March) and summer (from April to September) averages were thus calculated for the transport in the upper $1000 \mathrm{~m}$ of the model. The corresponding transport stream function fields are shown in Fig. 4, together with the over-all two-year
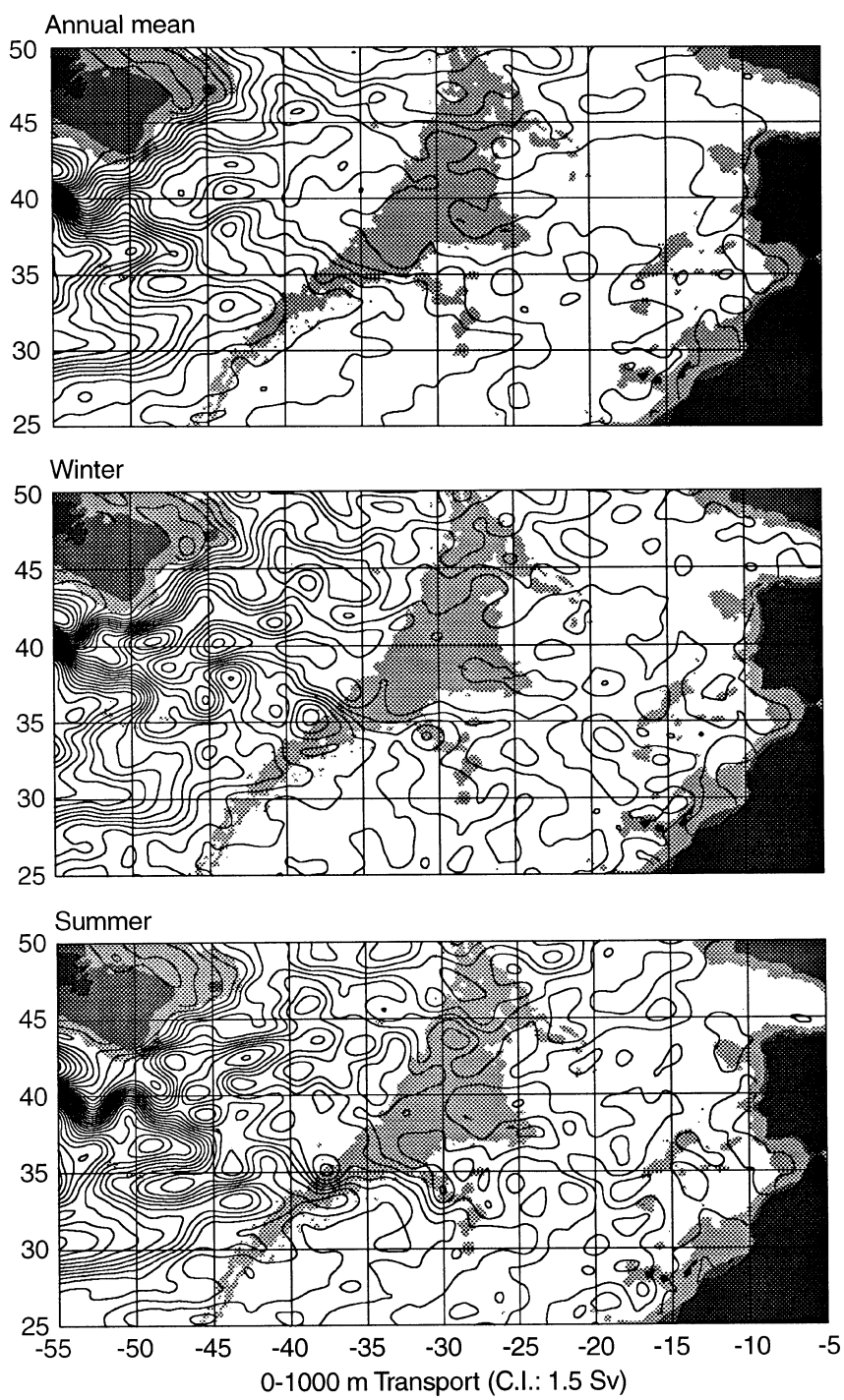

Fig. 4. Average transports between 0 and $1000 \mathrm{~m}$ as predicted by the model: yearly average, winter semi-annual average and summer semiannual average (CI: $1.5 \mathrm{~Sv})$. Shading corresponds to the regions where the depth is less than $3000 \mathrm{~m}$ average. These maps are directly comparable to those produced by Klein and Siedler (1989, their Fig. 8) using historical hydrographic data from the World Data Center A for oceanography. As mentioned earlier, this reveals the model mean transport, supplied by the assimilated MSSH, to be a little too weak in this region. Nevertheless, the richness of the altimetric residual information, and in particular the seasonal variability, has been well assimilated by the model.

Klein and Siedler (1989) found a noticeable difference between the winter and summer transport averages in the area where the Azores Current is fed by the Gulf Stream waters. In winter, the current is only fed by one branch which comes directly from the Gulf Stream, whereas in summer it is fed by two branches: a southern branch, which makes a loop towards the south-west before connecting to the Azores Current, and a smaller northern branch, which originates in the North Atlantic Drift.

It is interesting to note that this same behaviour is observed in our simulations, in both the years studied. Thus, in the winter period, a single branch in the 45$35^{\circ} \mathrm{W}, 35-40^{\circ} \mathrm{N}$ zone feeds the Azores Current. In summer, the current paths are quite different. One branch is clearly identified a little south of latitude $35^{\circ} \mathrm{N}$ where it makes a cyclonic loop centred on $34^{\circ} \mathrm{N}, 48^{\circ} \mathrm{W}$. This is also found by Klein and Siedler (1989). Two subregions of weaker transport intensity are also observed, one centred around $44^{\circ} \mathrm{W}, 37^{\circ} \mathrm{N}$ and located in the middle of the two branches feeding the current, the other centred around $37^{\circ} \mathrm{W}, 37^{\circ} \mathrm{N}$ over the MAR.

In addition, the simulation results shown in Fig. 4 reveal that, at $30^{\circ} \mathrm{W}$, the Azores Current is located further north in winter (north of $35^{\circ} \mathrm{N}$ ) than in summer (south of $35^{\circ} \mathrm{N}$ ). This observation is also in agreement with the results obtained by Klein and Siedler (1989). Stramma and Isemer (1988) and Stramma and Müller (1989) also noted a similar southward shift of the Azores Current during the summer season.

Two conclusions may be drawn. Firstly, the model succeeds in integrating the altimetric data information and then in reproducing the upper surface transport variability, especially at the seasonal scale. Secondly, since our results were obtained using entirely different observations and methods from those of Klein and Siedler (1989), this appears to confirm the solutions they proposed for the varying seasonal origins of the Azores Current. This would, therefore, appear to constitute a permanent feature of the North Atlantic ocean circulation. However, since the variability has significant energy at interannual and lower frequencies (Müller and Siedler, 1982), satellite observations in the forthcoming years will be helpful to confirm this conclusion definitely.

\section{Comparison with Lagrangian floats}

The comparisons made so far in this work have only concerned the instantaneous or time-averaged values of certain parameters. The assimilation of altimeter data, 
however, also makes it possible to reproduce the full spatio-temporal structure of the ocean circulation. Therefore it was interesting to compare instantaneous model predictions with independent measurements for the same times and locations. For this purpose, we were able to use the drifter dataset from the Semaphore experiment in 1993. Two types of drifters were launched during this survey: near surface drifters of the Surdrift type, drogued at a depth of $150 \mathrm{~m}$ and subsurface drifters of the Rafos type neutrally buoyant at a nominal depth of $2200 \mathrm{~m}$.

\section{Surface drifters}

As described by Hernandez (1995), these drifters had their drogue right below the mixed layer (150 $\mathrm{m}$ depth) and were aimed mainly at following the geostrophic currents. Indeed the surface float of these drifters was designed to minimise the effect of the wind and the nonlinear actions of waves such as the Stokes drift. Hernandez (1995) processed the trajectory data of each drifter to provide their position, and an estimate of their instantaneous velocity at this point every $6 \mathrm{~h}$. Note that frequencies greater than $(3 \text { days })^{-1}$ were removed using a Lanczos filter.

In the following statistical analysis, we have considered only those drifters for which at least 40 days of data were available. In addition, the data were sub-sampled by a factor of 4 , thus providing a daily sample. Data from 43 drifters were used therefore for periods varying from 41 to 131 days during the period from June to November 1993 (Fig. 5). Comparisons were made between the drifter instantaneous velocities and the instantaneous velocities computed from the model for the same locations and the same instants. Figure 6 shows an example for a specific drifter.

In general, as seen in Fig. 6, the zonal and meridional computed velocities are less than the drifter velocities. Two types of explanations can be envisaged. The first series of possible explanations relates to the model configuration and physics: the $150 \mathrm{~m}$ level lies between

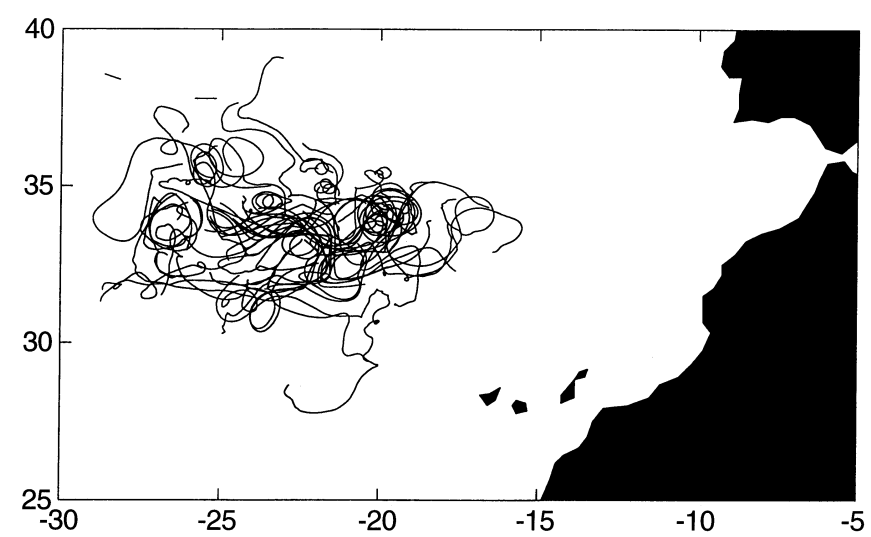

Fig. 5. Trajectory of the 43 surface drifters used from the Semaphore experiment
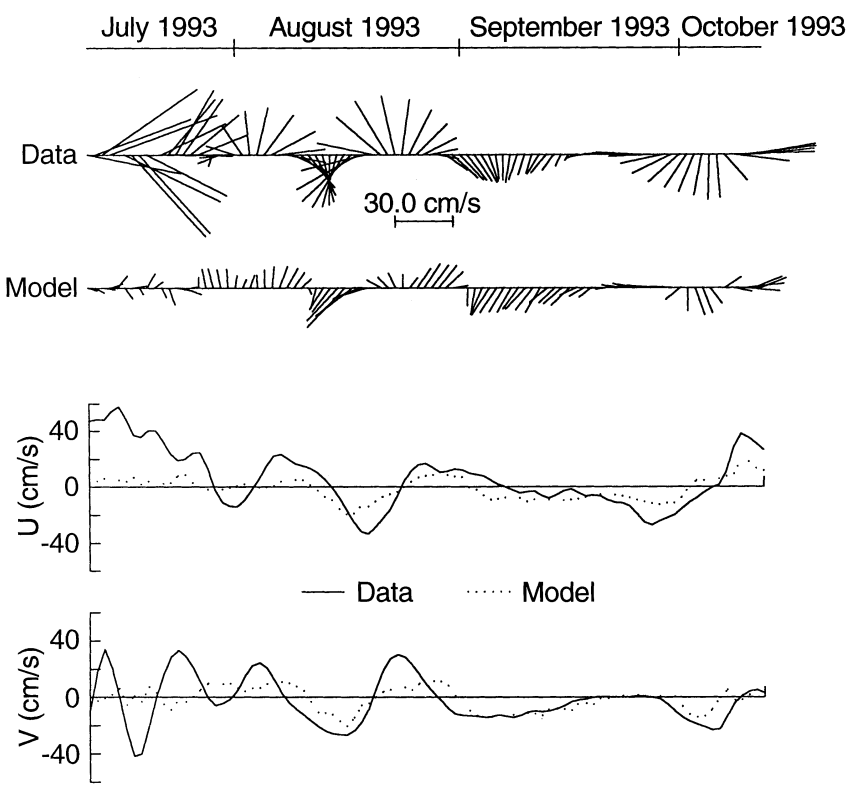

Fig. 6. Comparison of the velocities provided by the surface drifter 17543 (immersed at $150 \mathrm{~m}$ depth) and by the model along the drifter path. The vectorial correlation is 0.63

the first layer (centred at $50 \mathrm{~m}$ depth) and the second layer (centred at $200 \mathrm{~m}$ depth) and the computed velocity is interpolated from the respective velocities of the corresponding layers. Comparison of the vertical profile of horizontal velocity provided by the model with that deduced from current meter measurements, however, shows that the model velocity decreases more rapidly with depth than in reality, maybe because the model physics does not allow the information to correctly propagate vertically. The assimilation of altimeter data takes place in the upper layer and the velocities transmitted downwards to the model are underestimated. In addition, as already mentioned, the climatological relaxation at the boundaries tends to underestimate the mean velocities. The second likely source of discrepancy may come from the drifters themselves. Thus, peak velocities of 40 or even $50 \mathrm{~cm} / \mathrm{s}$ are recorded by the drifters compared with maximum velocities of $30 \mathrm{~cm} / \mathrm{s}$ measured by current meters for the same region and the same depth (Siedler et al., 1985). Morrow and De Mey (1995), in assimilating these drifter data in a regional numerical model using the variational approach, also observed that the currents created were stronger than those produced by the assimilation of altimeter data only. They also suspected that the geostrophic velocities of the drifters might be overestimated. However, it seems that it is a natural tendency of the floats to locate in the core of the current, where the velocity is maximum (Hernandez, personnal communication). This can also partly explain this discrepancy. In fact, the difference between the drifters and model velocities probably results from a combination of both causes.

The vectorial correlations between the surface drifter velocities and the model velocities were computed and 
Table 1. Vectorial correlation (total correlation and relative angles) between the surface drifter velocities and the corresponding model velocities. Column 4 represents the average velocity norm

\begin{tabular}{|c|c|c|c|c|}
\hline $\begin{array}{l}\text { Drifter } \\
\text { reference }\end{array}$ & $\begin{array}{l}\text { Total } \\
\text { correlation }\end{array}$ & $\begin{array}{l}\text { Relative } \\
\text { angle }\end{array}$ & $\begin{array}{l}\text { Drifter average } \\
\text { velocity norm }(\mathrm{cm} / \mathrm{s})\end{array}$ & $\begin{array}{l}\text { Days of } \\
\text { observation }\end{array}$ \\
\hline 17542 & 0.59 & -14.78 & 5.4 & 69 \\
\hline $17543^{*}$ & 0.63 & 1.91 & 10.6 & 93 \\
\hline 17544 & 0.63 & 2.36 & 7.1 & 110 \\
\hline 17545 & 0.36 & -33.82 & 7.1 & 57 \\
\hline 17546 & 0.26 & 16.63 & 9.5 & 91 \\
\hline 17547 & 0.53 & -.24 & 5.7 & 99 \\
\hline $17548^{*}$ & 0.52 & -10.22 & 8.7 & 107 \\
\hline 17549 & 0.54 & -6.94 & 5.8 & 131 \\
\hline $17550^{*}$ & 0.56 & -1.97 & 9.5 & 63 \\
\hline 17551 & 0.48 & 1.47 & 5.0 & 88 \\
\hline 17552 & 0.52 & 10.37 & 6.3 & 109 \\
\hline $17553^{*}$ & 0.57 & -5.18 & 9.6 & 107 \\
\hline $17554 *$ & 0.65 & 1.05 & 9.4 & 106 \\
\hline $17556^{*}$ & 0.55 & -17.78 & 9.5 & 53 \\
\hline 17557 & 0.37 & -22.05 & 4.9 & 105 \\
\hline 17558 & 0.30 & -60.17 & 3.8 & 86 \\
\hline $17559^{*}$ & 0.72 & 3.00 & 10.9 & 86 \\
\hline 17560 & 0.34 & -7.88 & 3.6 & 82 \\
\hline 17561 & 0.35 & 14.29 & 5.0 & 82 \\
\hline 17562 & 0.03 & -44.32 & 6.5 & 81 \\
\hline 17564 & 0.48 & -3.26 & 5.9 & 127 \\
\hline $17565^{*}$ & 0.77 & -2.84 & 8.4 & 82 \\
\hline 17566 & 0.27 & -30.75 & 5.1 & 82 \\
\hline 17567 & 0.26 & -23.77 & 6.3 & 82 \\
\hline 17569 & 0.34 & -33.32 & 5.7 & 75 \\
\hline 17570 & 0.64 & 8.60 & 5.7 & 92 \\
\hline $17571 *$ & 0.75 & 2.58 & 9.6 & 94 \\
\hline 17572 & 0.57 & 3.21 & 7.1 & 82 \\
\hline $17573^{*}$ & 0.47 & -19.43 & 8.6 & 52 \\
\hline 17574 & 0.76 & 8.55 & 7.4 & 51 \\
\hline $17575^{*}$ & 0.58 & -12.33 & 7.9 & 52 \\
\hline 17576 & 0.62 & 6.92 & 6.7 & 52 \\
\hline $17577^{*}$ & 0.52 & 15.98 & 10.0 & 85 \\
\hline $17578^{*}$ & 0.45 & 12.69 & 9.4 & 74 \\
\hline $17579 *$ & 0.44 & 10.88 & 7.7 & 50 \\
\hline $17581^{*}$ & 0.58 & 4.94 & 7.6 & 41 \\
\hline $17582^{*}$ & 0.58 & -13.64 & 7.9 & 66 \\
\hline 17583 & 0.33 & -14.92 & 4.6 & 119 \\
\hline 17584* & 0.69 & -1.47 & 10.0 & 62 \\
\hline $17585^{*}$ & 0.53 & 10.62 & 9.0 & 45 \\
\hline 17586 & 0.35 & -15.81 & 4.1 & 52 \\
\hline $17587^{*}$ & 0.76 & -16.08 & 11.3 & 50 \\
\hline $17588^{*}$ & 0.69 & -3.59 & 10.1 & 48 \\
\hline
\end{tabular}

* Drifter with mean velocities greater than $7.5 \mathrm{~cm} / \mathrm{s}$ are shown in Table 1. The vectorial correlation enables a comparison of two sets of vectors giving two numbers: the first is a total correlation mixing correlations on norms and directions, and the second is the estimated overall relative angle between the two sets. This method was used in an oceanographic context by Daniault et al. (1985) and Hernandez (1995). The average total correlation is 0.51 and the average of the absolute values of the relative angles is $12.9^{\circ}$. Despite the model's systematic underestimation of the velocities, as noted earlier, the relative changes are well reproduced, which explains the relatively good vectorial correlations obtained.

However, this average correlation conceals large disparities. Thus, some very weak correlations can be observed in Table 1, such as those for drifters 17558 and 17562. For some drifters, a weak correlation may result from a few points within a well-correlated ensemble.
More generally, however, it appears that when the drifter velocities are weak (average velocity norm less than $5 \mathrm{~cm} / \mathrm{s}$ ), the vectorial correlation is also small. Conversely, when the drifter velocities are high (average velocity norm of about $10 \mathrm{~cm} / \mathrm{s}$ ), the correlations are also high. This is, for example, the case in Fig. 6. In Fig. 7, we have plotted the total correlation between drifter and model velocities in relation to the corresponding average drifter velocity norm. It can actually be seen that the higher the drifter velocities, the better the total correlation between drifter velocities and model velocities. Let us compute, for example, the average vectorial correlation between the drifters and the model, selecting from Table 1 the drifters with mean velocities greater than $7.5 \mathrm{~cm} / \mathrm{s}$. An asterisk is placed near the reference number of these drifters in Table 1, 20 drifters in total. The average total correlation for these drifters is 


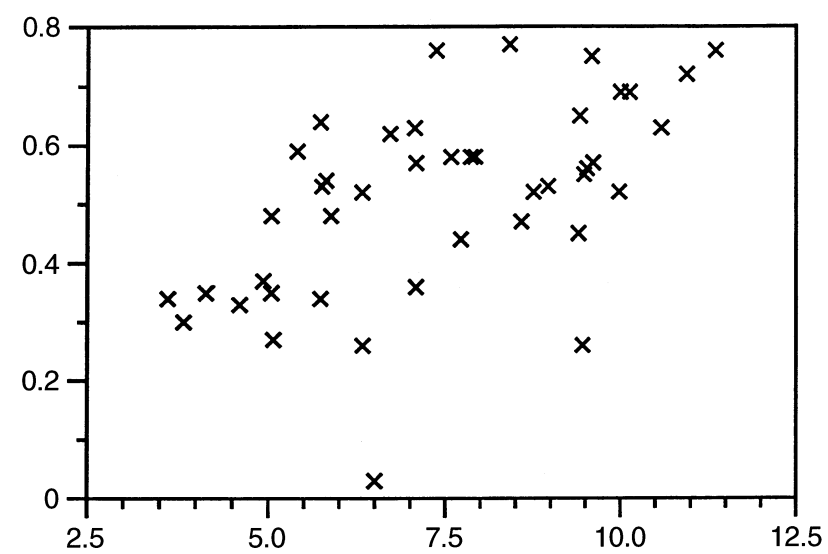

Fig. 7. Total correlation (see text) between the drifters and model velocities in relation to the average velocity norm of the drifters $(\mathrm{cm} / \mathrm{s})$

then 0.60 instead of 0.51 , while it is 8.4 instead of 12.9 for the average relative angle (in absolute values). It is thus found, once again, that if the drifter velocity is small, the corresponding altimetric signal is also weak and therefore the signal over noise ratio is important. In this case, we have probably reached the limits of accuracy with respect to controlling the surface circulation using our assimilation procedure.

\section{The Lagrangian sub-surface floats}

The data used in the assimilation process come from the surface only. The assimilation itself is relied upon to project the information downward so that the circulation can be correctly constructed over the vertical. Clearly this can only be carried out in an imperfect manner because of the limitations of the data assimilation technique. But the general paucity of observations in the deep ocean, even in the North Atlantic, makes it difficult to assess properly the model's predictions for the deep circulation. In addition, the model itself is dependent on the specifications of the climatological conditions at the open boundaries, which are poorly known. Using the Rafos subsurface floats it was possible to obtain some indication of the ability of the model to predict the deep circulation. These floats were actually immersed at a nominal depth of $2200 \mathrm{~m}$, a depth which is between levels 5 and 6 of the model. The method for comparing the observed data and the model results is the same as that used previously. An example is shown in Fig. 8. The agreement is generally poor at the lowest velocity levels but significant for the higher velocities. Table 2 presents the vectorial correlations for the 10 drifters at our disposal. The average total correlation is weak: $0.36\left(28.1^{\circ}\right.$ for the average of the absolute values of the relative angles). This demonstrates the limits of the model's capability to reproduce the deep circulations in this region. Again, the uncertainty of the boundary climatologies may be partly responsible for the discrepancy. In addition, it should be noted that the actual velocities are very small (typically $1 \mathrm{~cm} / \mathrm{s}$ ).

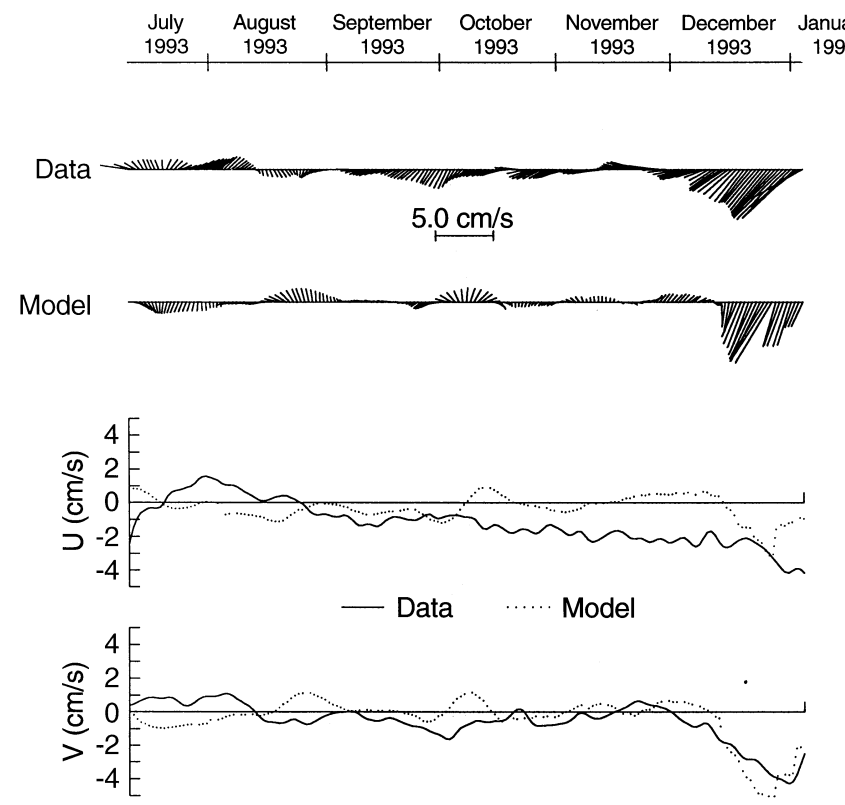

Fig. 8. Comparison of the velocities provided by the sub-surface drifter 17492 (immersed at $2200 \mathrm{~m}$ depth) and by the model along the drifter path. The vectorial correlation is 0.42

Table 2. Vectorial correlation (total correlation and relative angles) between the sub-surface drifter velocities and the corresponding model velocities

\begin{tabular}{llrl}
\hline $\begin{array}{l}\text { Drifter } \\
\text { reference }\end{array}$ & $\begin{array}{l}\text { Total } \\
\text { correlation }\end{array}$ & $\begin{array}{l}\text { Relative } \\
\text { angle }\end{array}$ & $\begin{array}{l}\text { Days of } \\
\text { observation }\end{array}$ \\
\hline 17492 & 0.43 & 5.72 & 178 \\
17498 & 0.27 & 23.25 & 178 \\
17501 & 0.08 & -0.10 & 176 \\
17502 & 0.65 & -70.98 & 176 \\
17504 & 0.31 & 12.90 & 448 \\
17507 & 0.33 & 47.02 & 176 \\
17508 & 0.59 & -52.46 & 108 \\
17510 & 0.56 & 12.41 & 176 \\
17512 & 0.33 & -14.42 & 177 \\
17515 & 0.09 & 41.79 & 176 \\
\hline
\end{tabular}

\section{Variability}

\section{Sea-level anomaly}

The map of sea-level Rms variability for the two years when data were available is shown in Fig. 9a. A zonal strip of higher variability may be observed at $34^{\circ} \mathrm{N}$ which corresponds to the Azores Front. In Fig. 9b, which shows the mean sea surface topography for the same time period, the Azores current can be seen in the same area as the strip of higher variability. The sea-level Rms reaches values between 5 and $9 \mathrm{~cm}$ within the Azores Front, with the maximum value of $9 \mathrm{~cm}$ at $30^{\circ} \mathrm{W}$. These are a little greater than the values computed by Le Traon and De Mey (1994) with the 1987-1988 Geosat data, although they also found the zonal strip of greater variability.

The Rms variability maps for individual years (Fig. 10a,c) reveal differences between the first and 

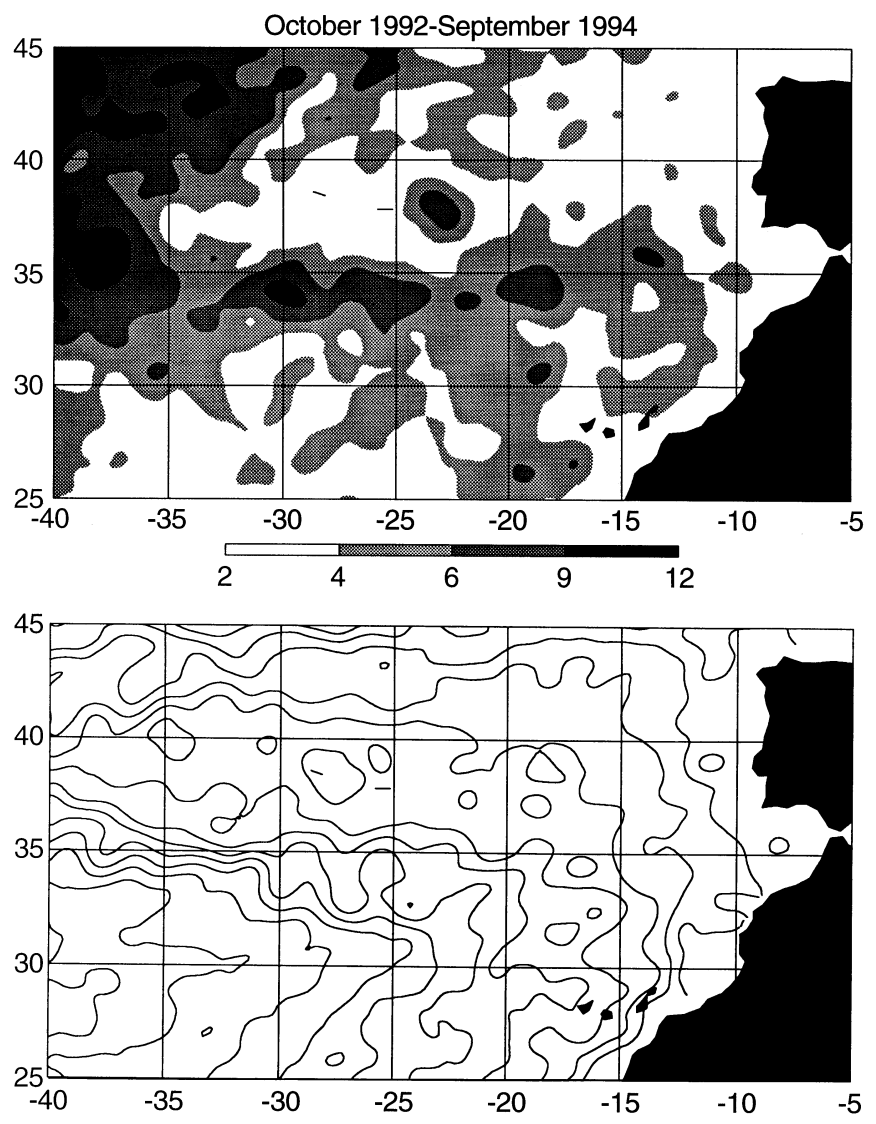

Fig. 9. a Map of the sea-level Rms variability over the two years of satellite observations (in $\mathrm{cm}$ ); b mean sea-surface topography for the same period (CI: $2 \mathrm{~cm})$

second years. The enhanced variability zonal strip at $34^{\circ} \mathrm{N}$ is, for example, quite narrow and relatively continuous from October 92 to September 93, whereas it is wider and discontinuous from October 93 to September 94. The visual coherency with the corresponding mean stream functions (Fig. 10b,d) is good. Thus, during the first year, the Azores Current becomes narrow at $34^{\circ} \mathrm{N}$ while, during the second year, it widens and does not penetrate as far to the east, making a cyclonic loop at $20^{\circ} \mathrm{W}$. Note that we are concerned here with the Azores Current, that is an average current, and that the Azores Front per se does not increase in size. This can be seen on the maps of the instantaneous dynamic topography in Fig. 2. The year from October 93 to September 94 was actually a year when the meridional extension of the meanders of the Azores Front was more marked.

The other prominent feature of the maps is the persistence of the high variability zonal strip up to $15^{\circ} \mathrm{W}$, while a large part of the flow from the Azores current goes southward before reaching $20^{\circ} \mathrm{W}$. This phenomenon was also observed and explained by Le Traon and De Mey (1994) using the 1987-1988 Geosat data base and an independent climatology from Robinson et al. (1979). They suggest that this variability results from the interaction of a Rossby wave originating on the eastern boundary with the eastward circula- tion of the Azores Current. This would justify a zonal structure, while a part of the current flows southward. This phenomenon seems to be persistent since it can also be observed in our simulation of the 1993-1994 period.

\section{Effect of bathymetry on variability}

The zonal strip of high variability exhibits relative maxima and minima which are observed for the whole two-year period as well as for each individual year. In order to examine a possible link with bathymetric variations, we compared the variability field maps (Figs. 9a, 10a,c) with a detailed bathymetric map of the region (Fig. 11). A clear correlation can be seen. If we consider first the high variability strip between $35^{\circ} \mathrm{W}$ and $15^{\circ} \mathrm{W}$, the three maps clearly exhibit two maxima: a maximum of $9 \mathrm{~cm}$ sea-level $\mathrm{Rms}$ at $30^{\circ} \mathrm{W}, 34^{\circ} \mathrm{N}$ and a maximum of 8 or $9 \mathrm{~cm} \mathrm{Rms}$ at $18.5^{\circ} \mathrm{W}, 34.5^{\circ} \mathrm{N}$. Between $25^{\circ} \mathrm{W}$ and $20^{\circ} \mathrm{W}$, variability is relatively weak, which corresponds precisely to greater bottom depths. This region of ocean deeps is clearly not propitious to mesoscale activity.

The extreme value at $18.5^{\circ} \mathrm{W}, 34.5^{\circ} \mathrm{N}$ lies directly over a marked topographic slope. It seems that this topographic slope, immediately upstream of the Madeira Islands, is an obstacle to the eastward circulation of the Azores Front (which is less energetic than at $30^{\circ} \mathrm{N}$ ) and thus strengthens the interaction between the front and the Rossby wave, as hypothesized by Le Traon and De Mey (1994). Note that, more generally, Spall (1992) explains that Rossby waves generated to the south of the Cape Verde Frontal Zone are also at the origin of the variability in the whole region.

The maximum at $30^{\circ} \mathrm{W}$ is clearly related to the shallower areas of the Atlantis Seamounts. When the Azores Front flows over these seamounts, it is destabilised, as is the Gulf Stream when it flows over the New England Seamounts (see Blayo et al., 1996), but to a lesser degree. As can be seen in Fig. 2, the Azores Front is well-structured upstream of the Atlantis Seamounts but much less downstream. Thus, some destabilisation of the jet occurs while passing over the Atlantic Seamount.

Another singular maximum for variability can be observed at $23^{\circ} \mathrm{W}, 37.5^{\circ} \mathrm{N}$, i.e. just east of the Azores Islands. Again bathymetric variations probably account for this phenomenon. It seems that eddies originating in the meanders of the Azores Front and travelling westward are trapped by the Azores Islands. This is most clearly reflected during the first year in the instantaneous sea-surface heights (Fig. 2). Thus mesoscale eddies can often be seen to the east of the Azores Islands. An interesting point is that this maximum for variability was also observed by Spall (1990), when analysing the results of the Community Modeling Effort model. Since this model does not reproduce the Azores Front meandering as well as our model does, another possible source for the high variability east of the Azores Islands could be the Rossby waves generated to the east and reaching the Azores Islands. 

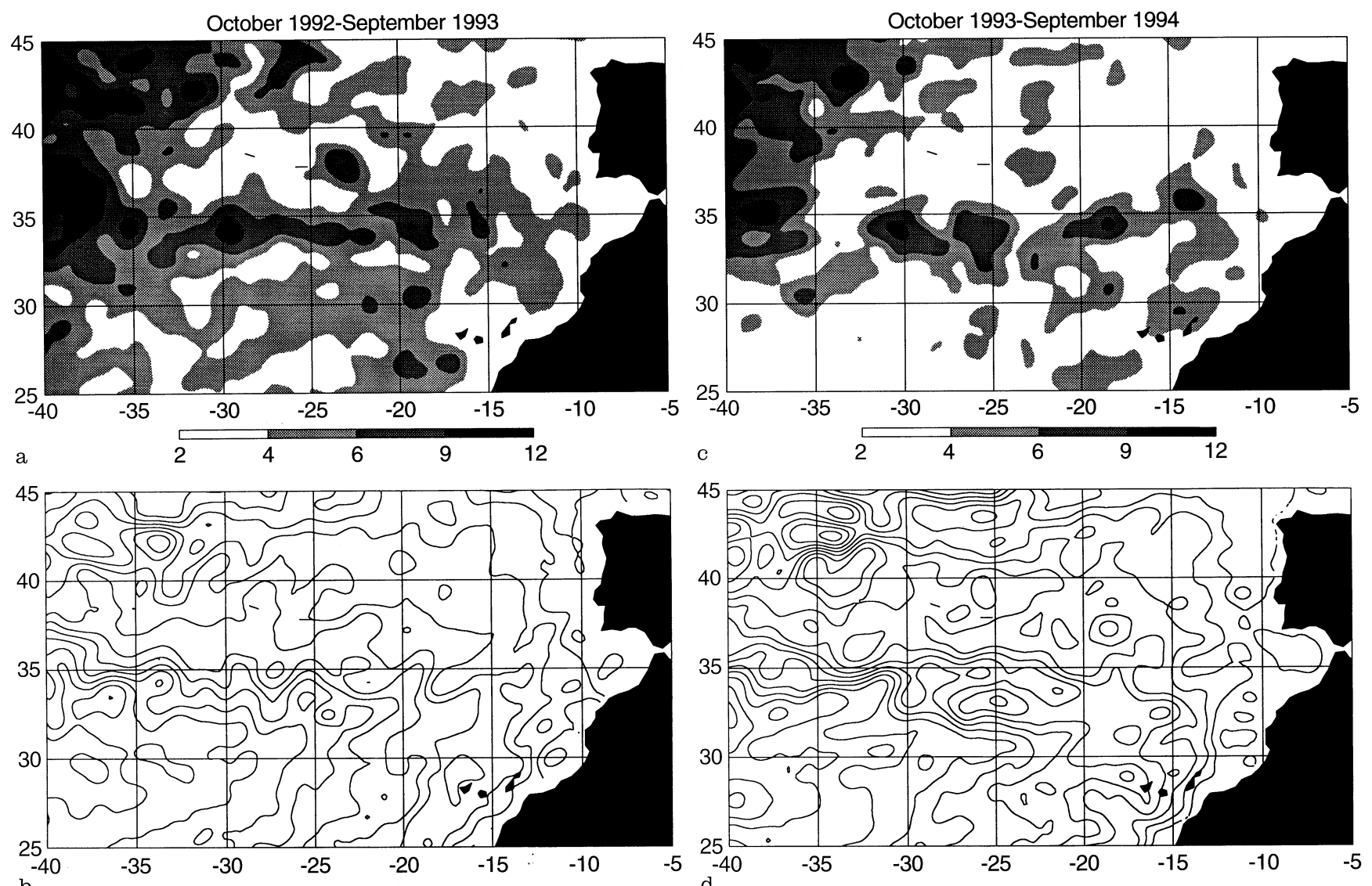

Fig. 10a, b. Same as Fig. 9 for the period from October 1992 to September 1993; c, d same as Fig. 9 for the period from October 1993 to September 1994

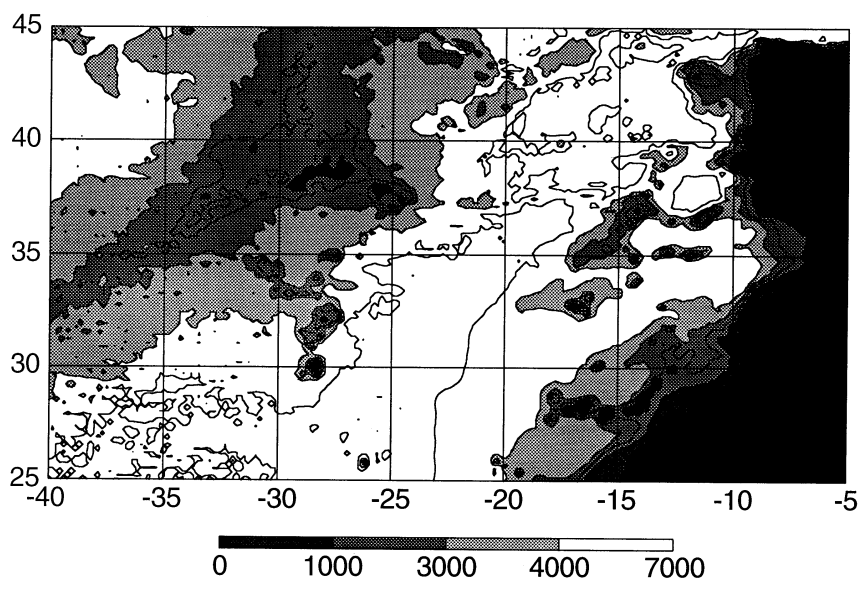

Fig. 11. Bathymetry of the Azores region. Contour intervals is $1000 \mathrm{~m}$

\section{The eddy kinetic energy}

The eddy kinetic energy (EKE) is also a major indicator of variability in the ocean circulation. Some examples of maps of the EKE fields at depths $50 \mathrm{~m}, 800 \mathrm{~m}$ and $3750 \mathrm{~m}$ are shown in Fig. 12 for the two years of simulation. Comparisons with other information of this type available in the literature are discussed later and reveal a fairly good level of general coherence.
Not surprisingly, the surface EKE field in Fig. 12a is quite analogous to the Rms field of sea-surface heights. In particular, at latitude $34^{\circ} \mathrm{N}$, the same strip of enhanced variability can be observed again with maxima at the same geographical locations. The EKE reaches values of 100 to $120 \mathrm{~cm}^{2} \mathrm{~s}^{-2}$ in the most active area. EKE maps were drawn from Lagrangian floats by Richardson (1983), who found values of $200 \mathrm{~cm}^{2} \mathrm{~s}^{-2}$ in the Azores Front using a very coarse dataset (3 drifters), and by Krauss and Käse (1984) who observed values of $100 \mathrm{~cm}^{2} \mathrm{~s}^{-2}$ near $30^{\circ} \mathrm{W}$, again with relatively coarse mapping over the Azores region. Using altimetric Geosat residuals computer over 2 years, Le Traon and De Mey (1994) obtained EKE values larger by about $30 \mathrm{~cm}^{2} \mathrm{~s}^{-2}$ than those predicted by our model. The variances of the meridional and zonal components of the model velocity were also computed (see Figs. 13 and 14). (Note that the EKE is the average of those two terms.) At $30^{\circ} \mathrm{W}, 34^{\circ} \mathrm{N}$, the curves show that the meridional velocity variance is almost three times larger than the zonal variance at $50 \mathrm{~m}$ depth. Over the domain in general (see Fig. 14 top), the variance of $V$ is always larger by a factor of 1.5 to 2 than the variance of $U$ above the thermocline in the area of the Azores current.

At $800 \mathrm{~m}$ depth (Fig. 12b), the patterns of the EKE are similar to the surface patterns. As expected, the values are weaker, with something like 3 to $7 \mathrm{~cm}^{2} \mathrm{~s}^{-2}$ for 

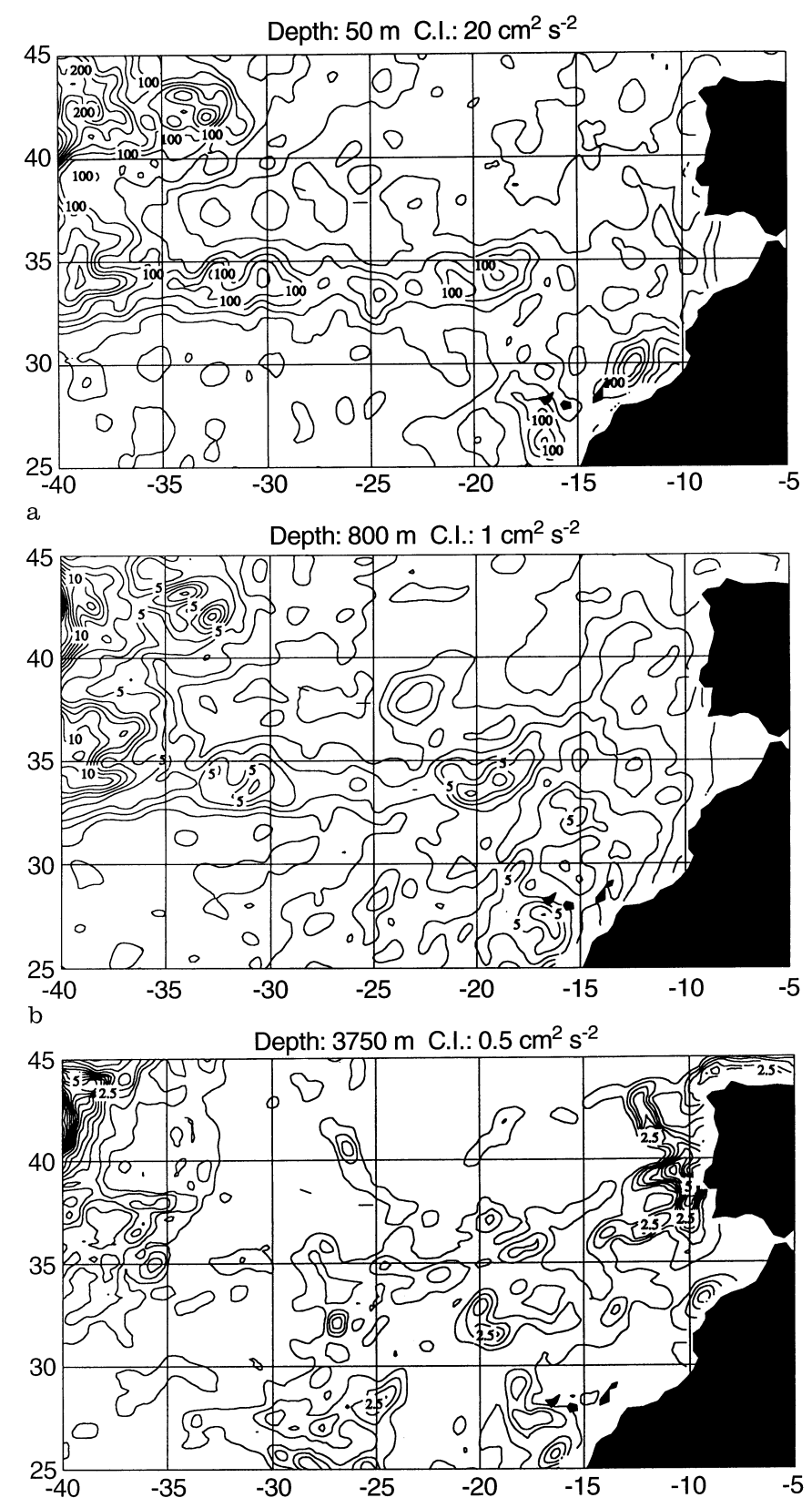

$\mathrm{C}$

Fig. 12a-c. Eddy kinetic energy computed over the two years of simulation. a At $50 \mathrm{~m}$ depth (CI: $20 \mathrm{~cm}^{2} \mathrm{~s}^{-2}$ ); b at $800 \mathrm{~m}$ depth (CI: $1 \mathrm{~cm}^{2} \mathrm{~s}^{-2}$ ); $\mathbf{c}$ at $3750 \mathrm{~m}$ depth (CI: $0.5 \mathrm{~cm}^{2} \mathrm{~s}^{-2}$ )

the Azores Current. This is in agreement with the study by Schmitz et al. (1988), who found values of $20 \mathrm{~cm}^{2} \mathrm{~s}^{-2}$ at $470 \mathrm{~m}$ depth and $5.9 \mathrm{~cm}^{2} \mathrm{~s}^{-2}$ at $1000 \mathrm{~m}$ depth at $24^{\circ} \mathrm{W}, 32^{\circ} \mathrm{N}$ from October 1984 to September 1986, and with the study by Zenk and Müller (1988) who observed an EKE value at $1000 \mathrm{~m}$ depth of between 5 and $15 \mathrm{~cm}^{2} \mathrm{~s}^{-2}$ (generally closer to 5) each year between 1980 and 1986 at $22^{\circ} \mathrm{W}, 33^{\circ} \mathrm{N}$. At this depth, the variance of $V$ is still greater than the variance of $U$ in the region of the Azores Front (Fig. 14 middle).

The model EKE at $3750 \mathrm{~m}$ depth is shown in Fig. 12c. Once again, a maximum of activity is found at $20^{\circ} \mathrm{W}$ arising from the surface activity of the Azores
Front, but this time it is located on the western boundaries of the Madeira Rise. There is also activity in the abyssal plain at $25^{\circ} \mathrm{W}$. Unlike at depths $50 \mathrm{~m}$ or $800 \mathrm{~m}$, the model EKE at $3750 \mathrm{~m}$ reveals an isotropic distribution of the variances of the velocity components (Fig. 14 bottom). This corresponds to the fact that at this depth, the flow is probably not zonal.

In general, the model EKE is in agreement with in situ observations though slightly weaker. This discrepancy may result from the assimilation technique itself which, as mentioned earlier, probably does not faithfully propagate downward all the information contained in the satellite data. However, we may note that models without satellite data assimilation produce a very much lower EKE in this region. It is the case for example with the Community Modeling Effort model: Spall (1990) observes a surface EKE less than $7 \mathrm{~cm}^{2} \mathrm{~s}^{-2}$ for the Azores Current, while Beckmann et al. (1994) observe very little increase of the EKE due to the Azores Current in their near-surface EKE versus longitude figure at $30^{\circ} \mathrm{W}$. Treguier (1992) also presents similar results.

\section{Temporal and spatial scales}

\section{Temporal scales}

To characterise the relevant flow time scales of the Azores Front, temporal spectra of the sea-level changes over time were computed for various locations in the region $\left(30-15^{\circ} \mathrm{W}, 32-36^{\circ} \mathrm{N}\right)$. Figure 15 , for example, shows the sea-level changes over time at $34^{\circ} \mathrm{N}, 26^{\circ} \mathrm{W}$ and the corresponding spectrum. The latter reveals several peak frequencies at $(365 \text { days })^{-1},(180 \text { days })^{-1}$, and $(60 \text { days })^{-1}$. A time series of two years is certainly too short to identify an annual signal but a peak corresponding to this frequency is however clearly visible on every spectrum and probably corresponds to a steric effect. Thus, throughout the domain, it was found that this annual signal corresponds to a sea-level increase during the summer season and to a sea-level decrease during the winter season (see, for example, Fig. 15a). Moreover, no peaks are observed at this frequency on the velocity spectra at the same locations. The peak frequencies at $(180 \text { days })^{-1}$ and $(60 \text { days })^{-1}$ in Fig. 15b are representative of what is observed on most sea-level and velocity spectra, namely peak frequencies around (200 days) $)^{-1}$ and between $(100 \text { days })^{-1}$ and $(50 \text { days })^{-1}$. This last frequency range is characteristic of the mesoscale activity. These values are also corroborated by Siedler et al. (1985) who used current meter measurements in the $33^{\circ} \mathrm{W}, 22^{\circ} \mathrm{W}$ region to identify strong velocity events with typical durations of 1 to 3 months, and by Le Traon and De Mey (1994) who observed an 80-day time scale Geosat data.

\section{Spatial scales}

The sea-level spectrum was computed along $34^{\circ} \mathrm{N}$ between $40^{\circ} \mathrm{W}$ and $10^{\circ} \mathrm{W}$ in order to identify the 

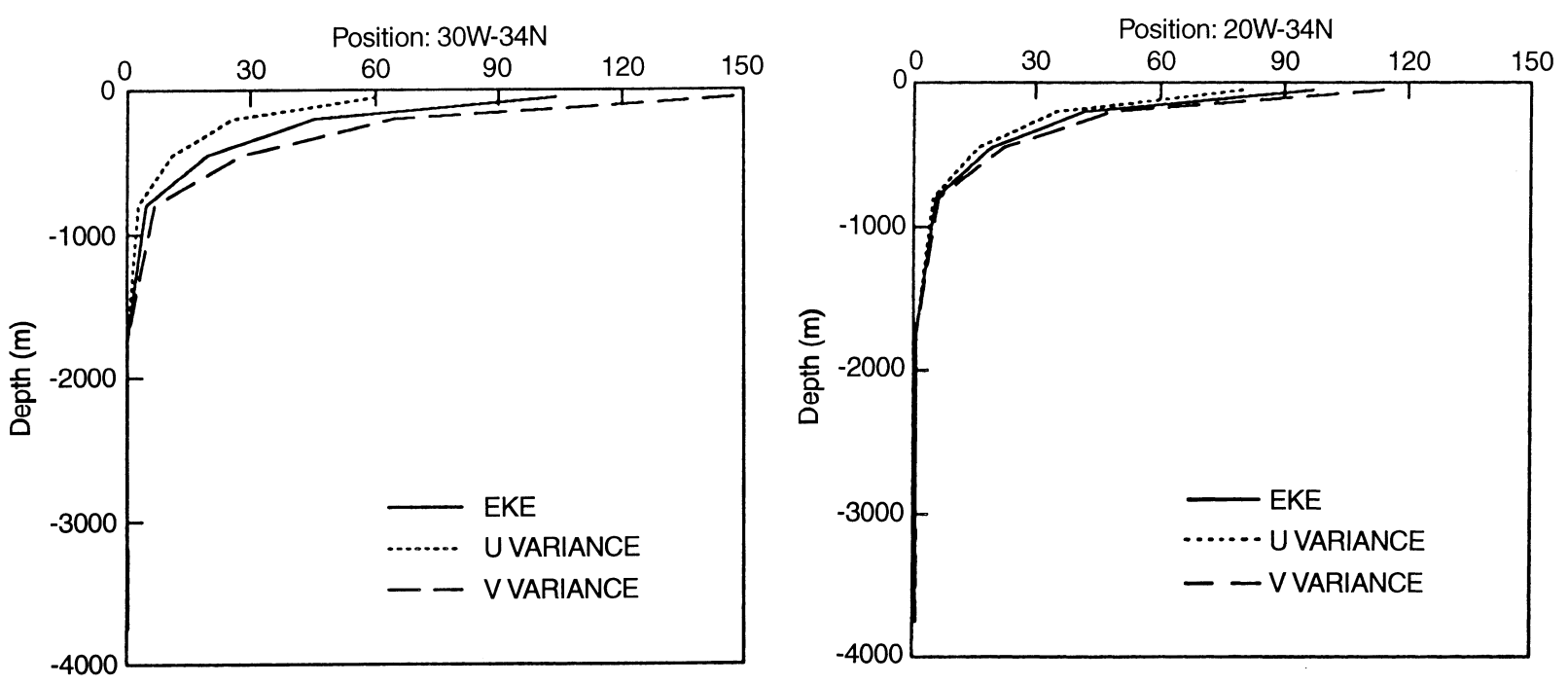

Fig. 13. Vertical profiles of the eddy kinetic energy, the variance of $U$ and the variance of $V$ computed over the two years of simulation at $30^{\circ} \mathrm{W}$, $34^{\circ} \mathrm{N}$ and at $20^{\circ} \mathrm{W}, 34^{\circ} \mathrm{N}$

\begin{tabular}{|c|c|c|c|c|c|c|c|}
\hline \multirow[b]{2}{*}{15} & \multicolumn{5}{|c|}{ Depth $50 \mathrm{~m}$} & \multicolumn{2}{|c|}{$\begin{array}{r}\text { EKE } \\
\text { VARIANCE U } \\
\text { VARIANCE V }\end{array}$} \\
\hline & 152.78 & 100.58 & 47.65 & 32.24 & 23.06 & 18.88 & 17.76 \\
\hline & 142.61 & 95.20 & 41.22 & 30.07 & 18.48 & 12.75 & 73.37 \\
\hline \multirow{3}{*}{40} & 162.96 & 105.96 & 54.08 & 34.40 & 27.62 & 25.01 & 2.16 \\
\hline & 97.39 & 46.96 & 28.37 & 37.82 & 29.85 & 39.09 & 24.17 \\
\hline & 85.67 & 40.36 & $23.79^{-}$ & 34.49 & 23.26 & 26.15 & 247 \\
\hline \multirow{3}{*}{35} & 109.11 & 53.56 & 32.95 & 41.15 & 36.45 & 52.04 & 32.86 \\
\hline & 84.27 & 62.10 & 55.06 & 58.55 & 61.42 & 60.06 & 29.31 \\
\hline & 79.99 & 55.19 & 40.77 & 56.23 & 49.46 & 45.31 & 1.99 \\
\hline \multirow{4}{*}{30} & 88.55 & 69.01 & 69.35 & 60.88 & 73.39 & 74.81 & 37.42 \\
\hline & 28.96 & 28.93 & 32.75 & 39.20 & 64.63 & 80.45 & \\
\hline & 23.46 & 22.62 & 24.33 & 31.16 & $51.55^{\circ}$ & $6 \longdiv { . 1 4 }$ & \\
\hline & 34.47 & 35.25 & 41.16 & 47.25 & 77.71 & 83.77 & \\
\hline & \multicolumn{7}{|c|}{ Depth 800 m } \\
\hline & 7.40 & 4.44 & 2.33 & 1.67 & 1.17 & 1.20 & 1.27 \\
\hline & 7.10 & 4.04 & 2.02 & 1.62 & .98 & .84 & 1.36 \\
\hline \multirow{4}{*}{40} & 7.71 & 4.83 & 2.64 & 1.72 & 1.35 & 1.55 & 1.17 \\
\hline & 6.44 & 2.15 & 1.38 & 2.42 & 2.01 & 2.02 & 83 \\
\hline & 5.50 & 1.80 & $1.29^{-}$ & 2.34 & 1.49 & 1.37 & \\
\hline & 7.37 & 2.49 & 1.48 & 2.49 & 2.54 & 2.67 & 23 \\
\hline \multirow{3}{*}{35} & 4.01 & 2.78 & 2.58 & 3.27 & 3.76 & 2.89 & en \\
\hline & 4.00 & 2.55 & 1.85 & 3.28 & 3.25 & 2.38 & 33 \\
\hline & 4.03 & 3.00 & 3.22 & 3.25 & 4.28 & 3.40 & 1.38 \\
\hline \multirow{3}{*}{30} & 1.53 & 1.65 & 2.35 & 2.88 & 3.97 & 2.97 & \\
\hline & 1.40 & 1.54 & 2.11 & 2.23 & $3.02^{\circ}$ & 2.07 & \\
\hline & 1.66 & 1.77 & 2.60 & 3.52 & 4.93 & 3.88 & \\
\hline & \multicolumn{7}{|c|}{ Depth $3750 \mathrm{~m}$} \\
\hline & 2.47 & .53 & .38 & .18 & .27 & .62 & 1.21 \\
\hline & 1.75 & .35 & .21 & .15 & .26 & .50 & 1.39 \\
\hline \multirow{3}{*}{40} & 3.19 & .70 & .55 & .20 & .29 & .75 & 1.03 \\
\hline & 1.32 & .46 & .30 & .40 & .49 & 1.07 & .78 \\
\hline & 1.40 & .42 & .31 & .45 & .51 & 1.06 & 47 \\
\hline \multirow{4}{*}{35} & 1.24 & .50 & .30 & .36 & .46 & 1.08 & $1.09=$ \\
\hline & .66 & .36 & .57 & .95 & .83 & .51 & .66 \\
\hline & .67 & .46 & .52 & .93 & .90 & .56 & .51 \\
\hline & .65 & .25 & .62 & .98 & .76 & .46 & .86 \\
\hline \multirow[t]{3}{*}{ Ju } & .35 & .51 & 1.14 & .87 & .76 & & \\
\hline & .40 & .68 & 1.33 & .60 & .7 & .30 & \\
\hline & .29 & .33 & .95 & 1.14 & .75 & .25 & \\
\hline & & & & & & & 0 \\
\hline
\end{tabular}

dominant spatial scales. Figure 16 shows a zonal section of the sea-level at $34^{\circ} \mathrm{N}$ on 15 January 1993 , and the corresponding spectrum. The spectrum contains a peak at $(600 \mathrm{~km})^{-1}$ and another at $(150 \mathrm{~km})^{-1}$. In general, peaks are found around $(600 \mathrm{~km})^{-1}$ and between $(300 \mathrm{~km})^{-1}$ and $(150 \mathrm{~km})^{-1}$. The latter range of wave lengths characterises the mesoscale activity in this region.

Two types of waves described by Le Traon and De Mey (1994) are reproduced: a first wave with $(600 \mathrm{~km})^{-1}$ wave number and (250 days) ${ }^{-1}$ frequency which corresponds probably to a Rossby wave generated in the east of the basin, and a wave of $(300 \mathrm{~km})^{-1}$ wave number and $(120 \text { days })^{-1}$ frequency which corresponds to a mesoscale undulation of the Azores Front. The latter wave has the same characteristics as the one observed by Spall (1992) near the Cape Verde Frontal Zone, and also described as a Rossby wave.

\section{Conclusion}

A detailed analysis was conducted of the results obtained for the Azores region by assimilating ERS-1 and Topex/Poseidon satellite altimetric data into a North Atlantic QG model. This work had two main objectives. The first was to assess the ability of this global model to correctly reproduce features of the North Atlantic ocean circulations which are relatively localised, specific, and of weak intensity (especially compared with the Gulf Stream system). The second aim was to use this model to conduct some oceanographic analyses in this key region of the northeast Atlantic.

Fig. 14. Local averages over $5^{\circ} \times 5^{\circ}$ boxes of the eddy kinetic energy, the variance of $U$ and the variance of $V$. Top at $50 \mathrm{~m}$ depth; middle at $800 \mathrm{~m}$ depth; bottom at $3750 \mathrm{~m}$ depth 

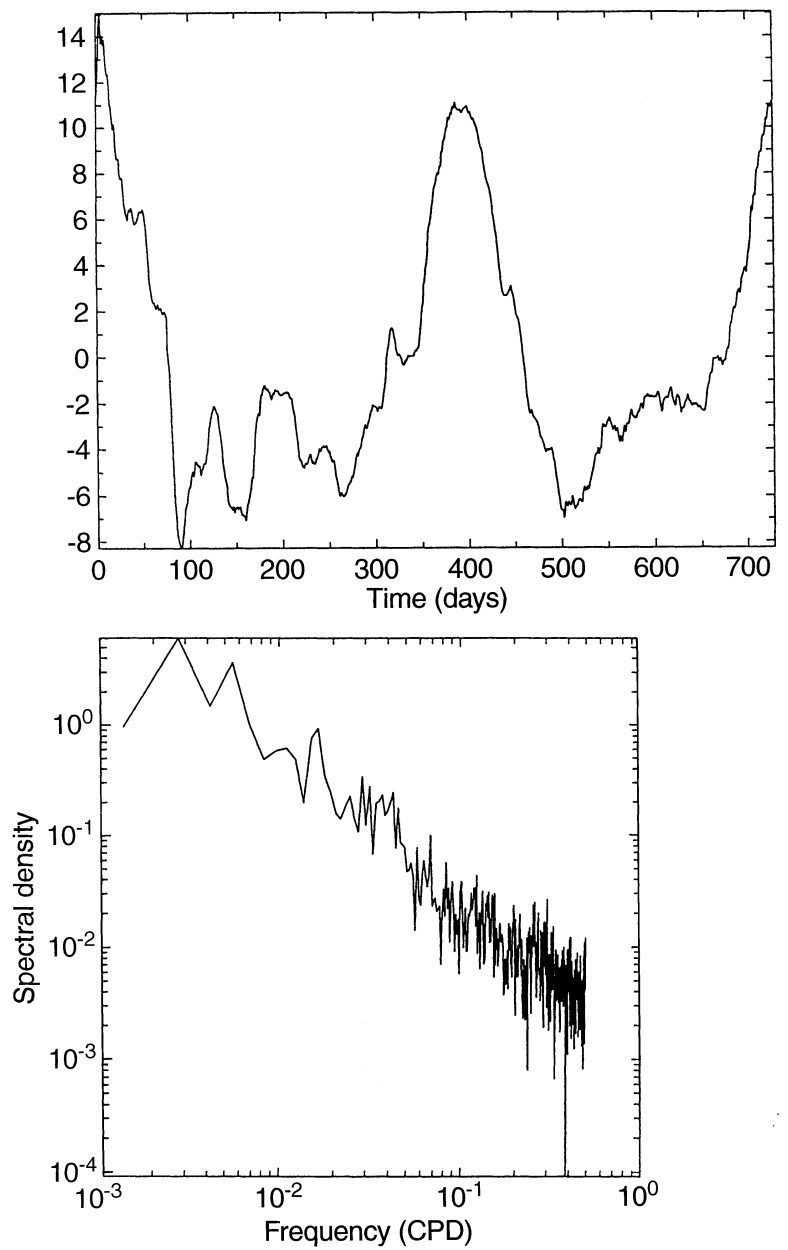

Fig. 15. Top: evolution of the sea-level at $\left[26^{\circ} \mathrm{W}, 35^{\circ} \mathrm{N}\right]$ over the two years of simulation $(\mathrm{cm})$; bottom: spectral density of this evolution

The accuracy of the predicted circulations was assessed according to several criteria. Firstly, the Azores Front and its meanders can easily be observed on the maps of instantaneous dynamic topography computed by the model. The model's predictions of the instantaneous velocities for the Azores Front are fairly accurate, although generally slightly smaller than available in situ observations. Perhaps more importantly, the instantaneous model velocities compare well with those provided by the drifters in the Semaphore experiment, with an average vectorial correlation of 0.60 for all the drifters having an average velocity greater than $7.5 \mathrm{~cm} / \mathrm{s}$. The mesoscale variability of the Azores Front is also well reproduced by the model. In particular, the zonal strip of high variability level along latitude $34^{\circ} \mathrm{N}$, as identified earlier by Le Traon and De Mey (1994) shows up clearly. Moreover, the EKE at $50 \mathrm{~m}$ and $800 \mathrm{~m}$ depths, as well as the characteristic time and space scales, are quite consistent with what is known of the circulation in this region.

Comparisons with sub-surface drifters, however, show that the model fails in part to reproduce the deep circulation in this region. At mid-depth, it must be kept
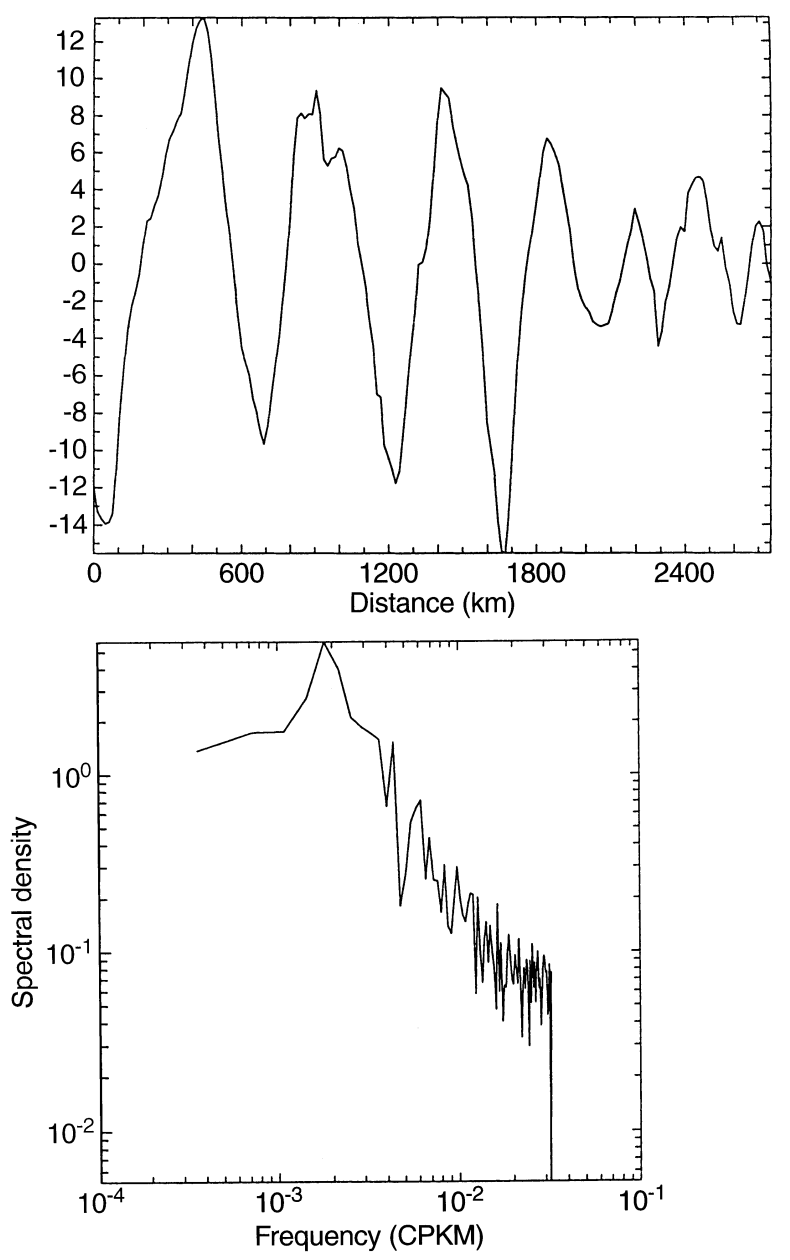

Fig. 16. Top: zonal section of the sea-level (in $\mathrm{cm}$ ) at $34^{\circ} \mathrm{N}$ latitude, between $40^{\circ} \mathrm{W}$ and $10^{\circ} \mathrm{W}$, on January 15,1993 ; bottom: spectral density of this section

in mind the Mediterranean water plays a role which is totally ignored here since no Mediterranean flows are included in the model. In addition, considerable uncertainty remains with regard to the specifications of the climatological deep circulations on the model boundaries. This clearly influences the model's ability to predict deep circulations.

As the model is able to reproduce the circulation and its variability, and provides us with continuous values of the parameters over the $2 \mathrm{y}$ of the experiment, it was also possible to carry out oceanographic analyses. The most interesting results obtained were as follows:

1. The observations by Klein and Siedler (1989) concerning the seasonal variation of the water masses which supply the Azores current are confirmed: one broad branch in winter and two branches in summer.

2. The strong interannual variability of the Azores Current is well reproduced in our simulations. In the first year of simulation (1992-1993), the current is quite narrow whereas in the second year (1993-1994) it is much wider, corresponding to greater meandering of the front. 
3. Mesoscale activity is strongly related to the presence of topographic slopes, suggesting that the bathymetry plays a significant role in this area.

Acknowledgements. We are indebted to P-Y Le Traon, to F. Hernandez, and to A. Tychensky for providing us respectively with the altimeter datasets, the SURDRIFT measurements and the RAFOS measurements. The calculations were made possible by the computer facilities at the Centre Grenoblois de Calcul Vectoriel (CGCV-CEA).

Topical Editor D. J. Webb thanks M. Spall and another Referee for their help in evaluating this paper.

\section{References}

Armi, L., and W. Zenk, Large lenses of highly saline Mediterranean water, J. Phys. Oceanogr., 14, 1560-1576, 1984.

Beckmann, A., C. W. Böning, B. Brügge, and D. Stammer, On the generation and role of eddy variability in the central North Atlantic Ocean, J. Geophys. Res., 99, 20381-20391, 1994.

Blayo, E., J. Verron, and J. M. Molines, Assimilation of Topex/ Poseidon altimeter data into a circulation model of the North Atlantic, J. Geophys. Res., 99, 24691-24705, 1994.

Blayo, E., J. Verron, J. M. Molines, and L. Testard, Monitoring of the Gulf Stream path using Geosat and Topex/Poseidon altimetric data assimilated into a model of ocean circulation, J. Mar. Syst., 8, 73-89, 1996.

Blayo, E., T. Mailly, B. Barnier, P. Brasseur, C. Le Provost, J. M. Molines, and J. Verron, Complementarity of ERS-1 and Topex/ Poseidon altimeter data in estimating the oceanic circulation: assimilation into a model of the North Atlantic, to appear in J. Geophys. Res., 1997.

Daniault, N., P. Blouch, and F. X. Fusey, The use of free-drifting meteorological buoys to study winds and surface currents, Deep-sea Res., 32, 107-113, 1985.

Eymard, L., S. Planton, P. Durand, et al., Study of the air - sea interactions at the mesoscale: the SEMAPHORE experiment, Annales Geophysicae, 14, 986-1015, 1916.

Ghil, M., and P. Malanotte-Rizzoli, Data assimilation in meteorology and oceanography, Adv. Geophys., 23, 141-265, 1991.

Hernandez, F., Comparison et combinaison des données altimétriques et des données de flotteurs lagrangiens: Application à la campagne Semaphore, PhD Thesis, Toulouse University, 340 pp., 1995.

Hernandez, F., P.-Y. Le Traon, and R. Morrow, Mapping mesoscale variability of the Azores current using Topex/Poseidon and ERS-1 altimetry, together with hydrographic and Lagrangian measurements, J. Geophys. Res., 100, 24995-25006, 1995.

Käse, R. H., and G. Siedler, Meandering of the subtropical front south-east of the Azores, Nature, 300, 245-246, 1982.

Käse, R. H., J. F. Price, P. L. Richardson, and W. Zenk, A quasisynoptic survey of the thermocline circulation and water mass distribution in the Canary basin, J. Geophys. Res., 91, 9739-9748, 1986.

Klein, B., and G. Siedler, On the origin of the Azores current, J. Geophys. Res., 94, 6159-6168, 1989.

Krauss, W., The North Atlantic Current, J. Geophys. Res., 91, 5061-5074

Krauss, W., and R. H. Käse, Mean circulation and eddy kinetic energy in the eastern North Atlantic, J. Geophys. Res., 89, 3407-3415, 1984.

Le Traon, P.-Y., and P. De Mey, The eddy field associated with the Azores Front east of the Mid-Atlantic Ridge as observed by Geosat altimeter, J. Geophys. Res., 99, 9907-9923, 1994.
Le Traon, P.-Y., P. Gaspar, F. Bouysseland, and H. Makhmara, Using Topex/Poseidon data to enhance ERS-1 data, J. Atmos. Oceanic Technol., 12, 161-170, 1995.

Maillard, C., and R. H. Käse, The near surface flow in the subtropical gyre south of the Azores, J. Geophys. Res., 94, 16133-16140, 1989.

Mercier, H., M. Ollitrault, and P. Y. Le Traon, An inverse model of the North Atlantic general circulation using Lagrangian float data, J. Phys. Oceanogr., 23, 689-715, 1993.

Morrow, R. A., and P. De Mey, Adjoint assimilation of altimetric, surface drifter, and hydrographic data in a quasi-geostrophic model of the Azores Current, J. Geophys. Res., 100, 25007$25025,1995$.

Müller, T. J., and G. Siedler, Multi-year current time series in the eastern North Atlantic Ocean, J. Mar. Res., 50, 63-98, 1995.

Richardson, P. L., Eddy kinetic energy in the North Atlantic Ocean from surface drifters, J. Geophys. Res., 88, 4355-4367, 1983

Robinson, M. K., R. A. Bauer, and E. H. Schroeder, Atlas of North Atlantic-Indian Ocean monthly mean temperature and salinity of the surface layer, Ref. Publ. 18, US Naval Oceanography Office, Washington D.C., 1979.

Schmitz, W. J., and M. S. McCartney, On the North Atlantic circulation, Rev. Geophys., 31, 29-49, 1993.

Schmitz, W. J., J. F. Price, and P. L. Richardson, Recent moored current meter and SOFAR float observations in the eastern Atlantic near $32^{\circ} \mathrm{N}, J$. Mar. Res., 46, 301-319, 1988.

Siedler, G., W. Zenk, and W. J. Emery, Strong current events related to a subtropical front in the northeast Atlantic, J. Phys. Oceanogr., 15, 885-897, 1985.

Spall, M. A., Circulation in the Canary Basin: a model/data analysis, J. Geophys. Res., 95, 9611-9628, 1990.

Spall, M. A., Rossby wave radiation in the Cape Verde Frontal Zone, J. Phys. Oceanogr., 22, 796-807, 1992.

Stommel, H., P. Niiler, and D. Anati Dynamic topography and recirculation of the North Atlantic, J. Mar. Res., 36, 449-468, 1978.

Stramma, L., Geostrophic transport in the warm water sphere of the eastern subtropical North Atlantic, J. Mar. Res., 42, 537-558, 1984.

Stramma, L., and H. J. Isemer, Seasonal variability of meridional temperature fluxes in the eastern North Atlantic Ocean, J. Mar. Res., 46, 281-299, 1988.

Stramma, L., and T. J. Müller, Some observations of the Azores current and the North Equatorial current, J. Geophys. Res., 94, 3181-3186, 1989.

Sy, A., Investigation of large-scale circulation patterns in the central North Atlantic: the North Atlantic current, the Azores current, and the Mediterranean water plume in the area of the mid-Atlantic ridge, Deep Sea Res., 35, 383-413, 1988.

Treguier, A. M., Kinetic energy analysis of an eddy resolving, primitive equation model of the North Atlantic, J. Geophys. Res., 97, 687-701, 1992.

Verron, J., Nudging altimeter data into quasigeostrophic ocean models, J. Geophys. Res., 99, 24584-24604, 1992.

Verron, J., and E. Blayo, The no-slip condition and separation of western boundary currents, J. Phys. Oceanogr., 26, 1938-1951, 1996.

Verron, J., J. M. Molines, and E. Blayo, Assimilation of Geosat data into a quasigeostrophic model of the North Atlantic between $20^{\circ} \mathrm{N}$ and $50^{\circ} \mathrm{N}$ : preliminary results, Oceanol. Acta, 15, 575-583, 1992.

Zenk, W., and T. J. Muller, Seven-year current meter record in the eastern North Atlantic, Deep Sea Res., 35, 1259-1268, 1988. 